Papel da praia na proteção da costa e as alterações oceanográficas em diferentes escalas temporais

\title{
Variabilidade morfológica e granulométrica e balanço sedimentar de uma praia em rotação praial
}

\author{
Morphological and granulometric variability and sedimentary budget of a \\ beach in rotation
}

Celia Regina de Gouveia Souza

Instituto Geológico-SMA/SP; Departamento de Geografia-FFLCH/USP

celiagouveia@gmail.com; celia@igeologico.sp.gov.br

\begin{abstract}
Resumo
A rotação praial é um fenômeno oscilatório, de curto a médio intervalo de tempo, caracterizado pela alternância entre erosão e acreção nas terminações opostas de praias de enseada, como resposta a modificações no transporte longitudinal, decorrentes de súbita mudança na direção/altura das ondas incidentes. Este trabalho apresenta as modificações na morfodinâmica, na granulometria e no balanço sedimentar decorrentes do fenômeno de rotação praial na Praia do Góes (município do Guarujá, São Paulo), em escalas de médio e longo termo. O fenômeno começou em fevereiro de 2010, pouco antes do início das obras de dragagem de aprofundamento do Canal do Porto. Entretanto, sua maior expressão se deu durante uma forte ressaca do mar no início de abril, quando a população local ficou isolada. Devido à localização da praia em uma pequena enseada no interior da Baía de Santos, em frente ao Canal de Acesso/Navegação do Porto de Santos, as rápidas modificações morfológicas ocorridas na praia foram atribuídas a um possível impacto da dragagem. O fenômeno foi estudado no âmbito do "Programa de Monitoramento do Perfil Praial", cujo objetivo é analisar possíveis impactos das obras de dragagem de aprofundamento do Porto de Santos nas praias locais. Cinco perfis praiais foram monitorados mensalmente, durante 36 meses entre janeiro/2010 e fevereiro/2014. Retroanálises em produtos de sensoriamento remoto de 1962 a 2011 serviram para identificar a ciclicidade histórica do fenômeno e obter o balanço sedimentar da praia de longo termo. Os resultados mostraram que o ciclo de rotação praial, ou de transporte de sentido horário, é impulsionado por inversões da deriva litorânea resultante predominante, causadas por eventos meteorológico-oceanográficos de forte magnitude (frentes frias com ressacas) e associadas a uma praia em completo desequilíbrio morfodinâmico antecedente. O intervalo de tempo decorrido entre o início do penúltimo ciclo (início em 1977) e o atual foi de 33 anos, sendo que a praia permaneceu em ciclo de rotação praial (maior deposição a leste e erosão a oeste) durante 13 anos, e levou cerca de 20 anos para atingir a total reversão do arco praial, em um ciclo de transporte de sentido anti-horário (maior deposição a oeste e extrema erosão a leste). A rotação atual causou intensa modificação morfológica, granulométrica e volumétrica na praia, em especial nas suas extremidades. O setor central da praia variou pouco, como esperado para o chamado ponto pivô da rotação praial. O balanço sedimentar de curto e médio termo pode ser considerado em equilíbrio, com tendências levemente positivas.
\end{abstract}

Palavras-chave: rotação praial; monitoramento praial; dragagem; Porto de Santos; Guarujá.

\begin{abstract}
Beach rotation phenomenon is a common occurrence in headland bay beaches, and is referred to a shift in alongshore sand transport between opposite extremities, which is attributed to periodic (short to medium-term) changes in wave climate, especially in wave direction/height. This paper reports the main changes in the beach morphodynamics, mean size of sands and sedimentary budget due to the beach rotation phenomenon in the Góes Beach (Guarujá Municipality, São Paulo). In spite of the present beach rotation started on February/2010, then before the dredging works in the Santos Port navigation channel, the strong morphological changes in the beach provoked by a severe storm surge on April, led to the local media to believe that these changes should be an impact of the dredging works. The phenomenon was studied on the context of the Beach Profile Monitoring Program, which objective is to evaluate possible impacts of the dredging works on the local beaches. The beach was monthly monitored through five profiles, during 36 months between January/2010 and February/2014. Back-analyses in remote sensing products from 1962 to 2011 were important for determining the transportation cycles of clockwise (beach rotation phases) and anti-clockwise, as well as the net beach sedimentary budget in long term. Results showed that these cycles are governed by longshore drift reversions caused by strong storm surges, associated to a prior unbalanced morphodynamic configuration. The duration of the last cycle was around 33 years, among them 13 years the beach kept itself in beach rotation (clockwise sediment transportation), and 20 years it has changed towards an
\end{abstract}


Papel da praia na proteção da costa e as alterações oceanográficas em diferentes escalas temporais

anti-clockwise transportation. Beach rotation caused strong morphological, volumetric and grain size changes, especially on the beach opposite ends. However, the central section of the beach remained almost unaltered, as expected for the pivotal point of the rotation. The net sedimentary budgets at short and long-terms may be considered in balance, with slight positive trends.

Keywords: beach rotation; beach monitoring; dredging; Santos Port; Guarujá.

\section{Introdução}

As costas rochosas representam cerca de $80 \%$ da linha de costa do planeta (Trenhaile 1987). Nelas encontram-se pequenas baías e enseadas que abrigam $51 \%$ das praias arenosas existentes no mundo (Short \& Masselink 1999). Historicamente, essas praias têm recebido várias denominações, sendo as mais comuns: praias de bolso, praias em forma de cabo de guardachuva, praias de baías crenuladas, praias parabólicas, praias embaiadas e praias de enseada (e.g. Silvester 1960, Finkelstein 1982, Carter 1988, Hsu \& Evans 1989, Silvester \& Hsu 1993, Short \& Masselink 1999).

A morfologia dos promontórios rochosos tem significativa influência na forma em planta, na incidência dos trens de ondas, no transporte longitudinal e transversal de sedimentos, e na morfodinâmica das praias de enseada (e.g. Carter 1988, Short \& Masselink 1999).

A forma em planta dessas praias geralmente é assimétrica, sendo caracterizada por três segmentos morfodinamicamente distintos: um segmento curto e reto voltado para a terminação mais exposta à ação de ondas (zona de barlamar natural da corrente deriva litorânea), uma zona central suavemente curvada, e um segmento longo e curvo formado na extremidade mais abrigada da ação de ondas, ou seja, na zona de sombra da enseada (zona de sotamar natural da corrente de deriva litorânea).

As praias de enseada são normalmente afetadas pela transferência de sedimentos, em meio subaquoso, ao longo dos promontórios (e.g. Short et al. 2000), pela formação de correntes de retorno associadas a ondas de borda e estacionárias (e.g. Holman et al. 2006), pelo desenvolvimento de mega-cúspides (e.g. Masselink 1999, Ojeda et al. 2006) e pela rotação praial (e.g. Short \& Masselink 1999).

A rotação praial é um fenômeno oscilatório, de curto (sazonal) a longo período de tempo, observado em praias de enseada, e que corresponde a um realinhamento da praia (modificação na orientação da linha de costa) em resposta a inversões no transporte litorâneo longitudinal entre as extremidades opostas da praia, resultando na alternância entre erosão e acreção nessas terminações (e.g. Short \& Masselink 1999, Short et al. 1999) (figura 1). O fenômeno pode ser definido pelo avanço/retração da linha de costa, máximo junto às extremidades da praia e mínimo na sua seção central, onde se localiza o ponto pivô (pivotal point) (Short et al. 2000, Ojeda \& Guillén 2008).

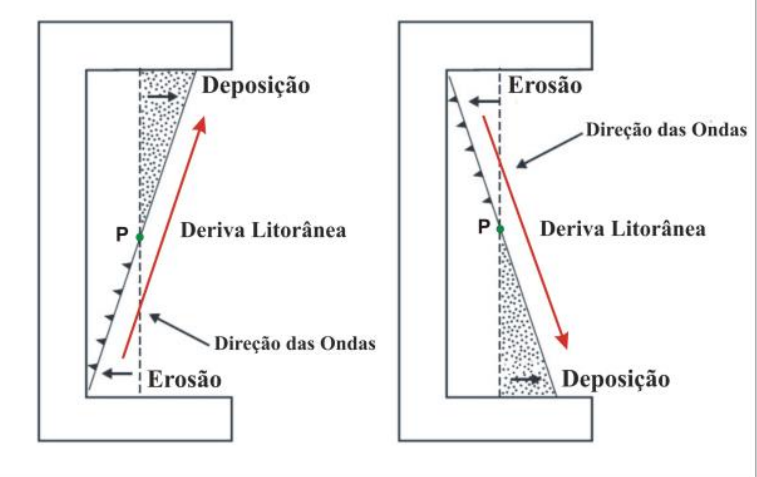

Figura 1: Modelo esquemático do fenômeno de rotação praial (modificado de Souza \& Luna 2010, com base em Short \& Masselink 1999 e Ojeda \& Guillén 2008). P = Ponto Pivô.

As inversões na deriva litorânea que desencadeiam a rotação praial são causadas por mudança súbita, mas periódica (sazonal ou de até longo período), no clima de ondas incidentes na costa, em especial na sua direção e altura, associada a eventos de alta energia de ondas, como tempestades e ressacas do mar (Short \& Masselink 1999, Short et al. 1999, Short et al. 2000, Klein et al. 2002, Ranasinghe et al. 2004, Short \& Trembanis 2004, Sedrati \& Anthony 2007, Ojeda \& Guillén 2008, Fairley et al. 2009, Alegria-Arzaburu \& Masselink 2010, Martins et al. 2010, Alencar et al. 2011, Archetti \& Romagnoli 2011). Depreende-se então, que a rotação praial é um fenômeno controlado por pulsos.

Alguns autores também encontraram relações entre esses eventos de alta energia de ondas e fenômenos climáticos de larga escala como o ENOS - El Niño e Oscilação Sul (Short et al. 2000, Short \& Trembanis 2004, Anthony et al. 2002, Ranasinghe et al. 2004, Rooney \& Fletcher 2005) e a Oscilação do Atlântico Norte (Thomas et al. 2010, 2011).

Por outro lado, para Anthony et al. (2002), a causa principal da rotação praial e uma praia da Guiana Francesa, foi o padrão de migração de bancos de lama na desembocadura do Rio Amazonas, o qual, por sua vez, também deve ser controlado por eventos meteorológico-oceanográficos de alta energia.

Independente das causas, a rotação praial e o clima de ondas parecem apresentar uma complexa relação entre si, já que tempestades similares podem causar diferentes efeitos em uma mesma praia ao longo do tempo, ou em praias adjacentes durante um mesmo evento, dependendo do grau de configuração morfodinâmica em que a(s) praia(s) se encontra(m) (e.g. Morton et al. 1995, Lee et al. 1998, Newe et al. 1999, Short 1999, Cooper et al. 2004, Quartel et al. 2008, Ojeda \& Guillén 2008, Ojeda et al. 2010, Archetti \& Romagnoli 2011). 
Papel da praia na proteção da costa e as alterações oceanográficas em diferentes escalas temporais

Em outras palavras, o impacto de uma tempestade em uma praia dependerá não somente das forçantes atmosféricas (duração da tempestade, intensidade dos ventos) e das características das ondas (direção e altura das ondas) e das marés (sizígia/quadratura, maré meteorológica, correntes de maré), mas também muito da morfologia antecedente dessa praia. Esta última, por sua vez, é controlada pela sazonalidade e também pela atuação de eventos meteorológico-oceanográficos cujos efeitos são cumulativos, tais como, a ocorrência de sucessivas ressacas em uma praia, ou a permanência de condições de tempo bom, sem perturbações no clima de ondas por um período de tempo prolongado.

A duração de um ciclo de rotação praial pode persistir num intervalo de tempo desde dias (e.g. Martins et al. 2010, Klein et al. 2002) até cerca de uma década (Short \& Masselink 1999, Short et al. 1999, Short et al. 2000, Ranasinghe et al. 2004, Short \& Trembanis 2004, Sedrati \& Anthony 2007, Ojeda \& Guillén 2008, Fairley et al. 2009, Alegria-Arzaburu \& Masselink 2010, Alencar et al. 2011, Alencar Jr et al. 2011, Archetti \& Romagnoli 2011). É frequente não envolver ganhos ou perdas no balanço sedimentar de longo termo, porque a praia frequentemente retorna ao estado original em resposta a novas mudanças na direção das ondas (Short \& Masselink 1999, Klein et al. 2002, Ojeda \& Guillén 2008).

Além da inversão repentina do transporte longitudinal (deriva litorânea), responsável pela reorientação da linha de costa e a transferência lateral de volumes de sedimento, a rotação praial também vem acompanhada por mudanças no transporte transversal à costa (costa-adentro/costa-afora), que determinam interações entre as porções subaérea e submersa (barras e bancos submersos) do perfil praial (Short \& Masselink 1999, Ojeda \& Guillén 2008).

Em resumo, durante o fenômeno de rotação praial, os processos sedimentares não serão constantes ao longo da praia e do tempo, devido à influência de vários mecanismos naturais e até induzidos por intervenções antrópicas, tais como: trocas de sedimentos entre as porções subaérea e submersa da praia (transportes costa-adentro/costa-afora); formação e migração de feições sedimentares de fundo (bancos e barras arenosos); entrada de sedimentos na praia por meio dos rios, de transferências ao longo dos promontórios, de transporte eólico ou de alimentação artificial da praia; saída de sedimentos da praia por meio de correntes de retorno, transporte eólico e retirada de areia de praia; e outras modificações no balanço sedimentar causadas por intervenções antrópicas na linha de costa (ex. obras de proteção costeira), implantação de barragens em cursos fluviais e dragagens.

Klein et al. (2002) também verificaram que há uma relação importante entre a mobilidade dos perfis praiais (variações de largura e de volume ao longo do tempo) e a curvatura das praias de enseada, tal que: em praias de acentuada curvatura os perfis localizados na área de maior curvatura, ou seja, na zona de sotamar (zona de sombra) apresentam menor mobilidade, enquanto os perfis localizados na extremidade mais reta e mais exposta da praia (zona de barlamar) têm maior mobilidade; em praias de menor curvatura, com forma em planta mais reta (menor zona de sombra), os perfis desenvolvem menores variações ao longo de toda a praia.

Levando em consideração todos esses conceitos, é de se esperar que em praias mais expostas à ação direta das ondas o ciclo da rotação praial se desenvolva em menor intervalo de tempo do que em praias mais abrigadas (como a Praia do Góes, por exemplo), nas quais os processos serão naturalmente mais lentos e muito dependentes dos eventos meteorológicooceanográficos mais intensos.

No Brasil, as praias de enseada ocorrem principalmente nos estados do Rio de Janeiro (a partir de Cabo Frio), São Paulo, Paraná e Santa Catarina (até o Cabo de Santa Marta), trechos do litoral Sudeste e Sul do Brasil que estão sob o domínio da Serra do Mar, que avança sobre a linha de costa. Entretanto, cabe mencionar que a presença de recifes e de falésias do Grupo Barreiras nas regiões Leste e Nordeste brasileiras, também contribui para a formação de inúmeras e pequenas praias de enseada.

Mesmo assim, ainda são poucas as referências sobre o fenômeno da rotação praial no Brasil, citadas apenas para algumas praias de Santa Catarina (e.g. Klein et al. 2002) e São Paulo (Souza et al. 2009, Martins et al. 2010, Souza 2011, 2012).

O presente trabalho descreve a ocorrência e as consequências do desenvolvimento do fenômeno de rotação praial na Praia do Góes (município do Guarujá, São Paulo), observadas durante três anos de monitoramento (2010-2011 e 2013-2014), bem como demonstra a ciclicidade histórica do mesmo e a sua independência em relação às obras de dragagem de aprofundamento do Canal do Porto de Santos.

Esse monitoramento ocorreu no âmbito do "Programa de Monitoramento do Perfil Praial para Averiguação de Possíveis Impactos das Obras Dragagem de Aprofundamento do Canal de Acesso e Navegação do Porto de Santos" (PMPPr) (Souza et al. 2011). As obras começaram em março de 2010, a partir da área mais oceânica do canal, junto à barra da Baía de Santos, e se estenderam até meados de 2011, quando a dragagem atingiu os berços de atracação interiorizados no Estuário de Santos. Os objetivos previstos foram o aprofundamento do canal de 13 para até $15 \mathrm{~m}$, e o seu alargamento de 150 para até $220 \mathrm{~m}$. O trecho em frente à Praia do Góes, já com profundidades naturalmente mais elevadas, em torno de $15-16 \mathrm{~m}$, foi pouco alterado, sendo que as dragas operaram nessa área apenas entre setembro-outubro de 2010.

O ciclo atual de rotação praial na Praia do Góes se iniciou em fevereiro/2010. No início de abril, um ciclone extratropical avançou sobre a Baixada Santista, gerando uma ressaca do mar de muito forte intensidade, com ondas de até $4 \mathrm{~m}$ de altura na parte externa da Baía de Santos. No dia 07 de abril a Praia do Góes foi atingida por ondas de até $2,0 \mathrm{~m}$, que 
Papel da praia na proteção da costa e as alterações oceanográficas em diferentes escalas temporais

intensificaram as modificações morfológicas provocadas pela rotação praial em curso. Por razões óbvias, o fenômeno foi rapidamente associado às obras de dragagem, gerando polêmica em torno dos seus impactos nas praias e das expectativas em relação à compensação ambiental por parte da CODESP (Companhia de Docas do Estado de São Paulo).

\section{2. Área de Estudo}

A Praia do Góes está localizada ao fundo da pequena e abrigada Enseada do Góes, encravada no embasanento cristalino no extremo oeste da Ilha de Santo Amaro, município do Guarujá (Região Metropolitana da Baixada Santista), litoral central de São Paulo (figura 2). A localização dos cinco perfis praiais que estão sendo monitorados é exibida na figura em detalhe.

Até a década de 1980 a praia era habitada por uma colônia de pescadores artesanais, a qual foi sendo gradualmente substituída por migrantes vindos da cidade de Santos. O principal acesso a ela sempre foi por meio marítimo, por um serviço de tracaias. Na maior parte do tempo, o píer de atracação fica localizado no setor leste da praia, entre os perfis Góes05 e Góes-04 (vide figura 2-detalhe). Entretanto, em determinadas épocas, a exemplo do que ocorria na década de 1980 e a partir de 2012, a atracação passa a ser feita num píer ancorado no promontório rochoso do setor ocidental da enseada. Como discutido adiante, essas mudanças no local de atracação estão intimamente atreladas à ocorrência do fenômeno da rotação praial.

Além do acesso marítimo, uma trilha com críticos problemas de erosão e escorregamentos circunda o promomtório oriental da enseada, e liga a praia à comunidade da Santa Cruz dos Navegantes, onde se encontra a Fortaleza da Barra, patrimônio histórico construído no século XVII. Restos de uma provável estrutura de vigia, anexa a essa fortaleza, ancoram a vertente íngreme do embasamento na extremidade leste da Praia do Góes, formando uma muralha de pedras denominada "Fortim do Góes", que também é patrimônio histórico.

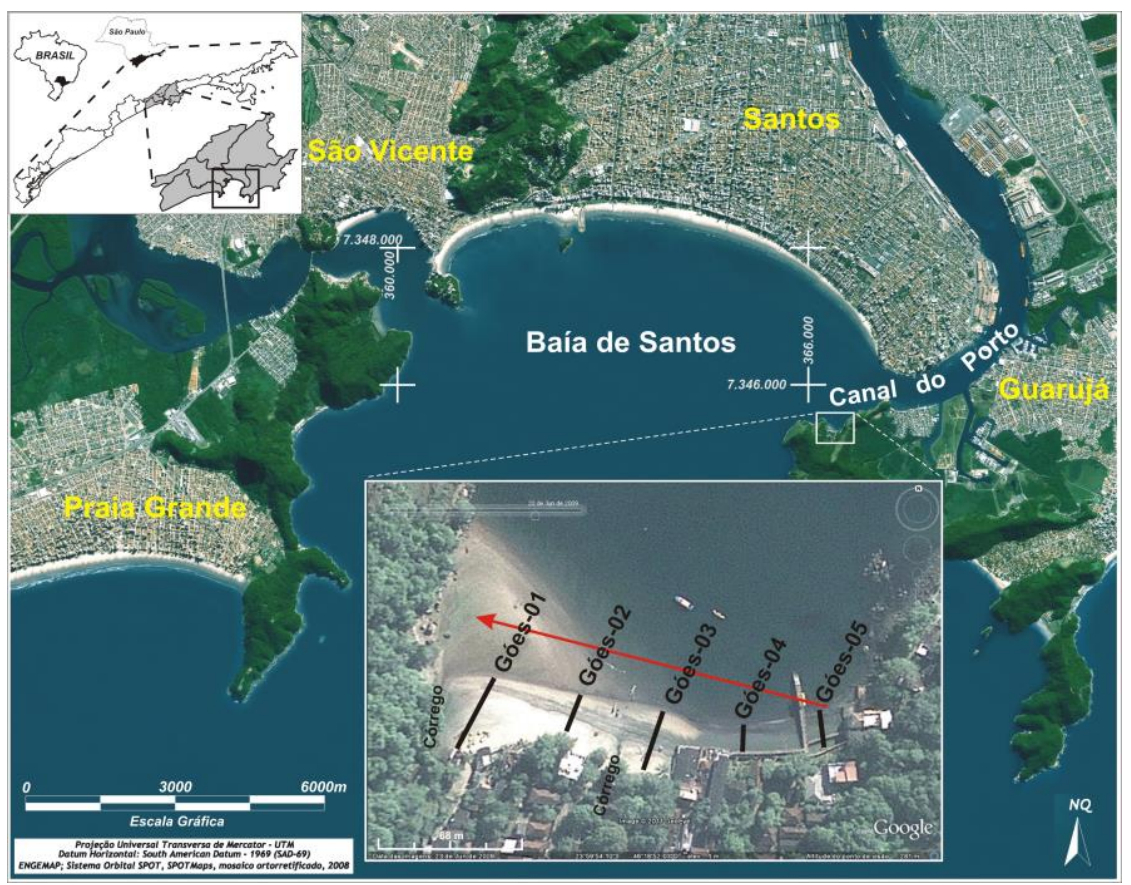

Figura 2: Localização da Praia do Góes. A imagem no detalhe (Google Earth GeoEye, de 23/06/2009), obtida em fase de baixamar de sizígia após uma ressaca de forte magnitude, exibe a localização dos perfis de monitoramento, numa situação anterior à rotação praial. Notar a erosão acelerada entre os perfis Góes-04 e Góes-05, e a maior acumulação de sedimentos no perfil Góes-01, indicando deriva litorânea resultante de leste para oeste (seta vermelha). O intenso assoreamento no setor ocidental da Enseada do Góes sugere uma mega-corrente de retorno alimentada pela deriva litorânea.

A fisiografia costeira da Enseada do Góes, de orientação leste-oeste e voltada para norte, faz com que a Praia do Góes seja completamente abrigada da incidência direta dos trens de ondas do mar aberto, mas influenciada somente pelas ondas provenientes da Baía de Santos, alteradas por fenômenos de difração, refração e reflexão.

O setor ocidental da Enseada do Góes é naturalmente o mais abrigado da ação das ondas (zona de sombra), enquanto o setor oriental é o mais exposto. Como consequência, na maior parte do tempo a zona de barlamar natural da corrente de deriva litorânea resultante se encontra no setor leste da praia, enquanto a zona de sotamar natural se localiza no outro extremo (setor oeste). Essa dinâmica natural gera e alimenta uma mega-corrente de retorno ao longo do promontório ocidental da enseada, que promove ali grande estocagem de areias médias até muito finas (vide figura 2-detalhe). A acumulação dessas areias por um longo período e a muito baixa energia de retrabalhamento no local acabam desencadeando um desajuste morfológico no fundo que, como será discutido adiante, favorece a ocorrência da rotação praial. 
Papel da praia na proteção da costa e as alterações oceanográficas em diferentes escalas temporais

As pequenas ondas colapsantes que arrebentam na face praial são, em geral, de baixa energia. Durante os monitoramentos as médias das alturas máximas medidas foram de $0,12 \mathrm{~m}$ para condições de tempo bom, e de 1,1 m para condições de ressaca. Ondas induzidas por embarcações de pequeno porte, que circulam no interior da enseada, também são frequentes. Como consequência, não é raro observar uma complexa trama de trens de ondas com direções, comprimentos, períodos e energias diferentes, atuando ao longo da praia.

Essas características, por si só, indicam que na Praia do Góes os processos costeiros têm evolução bastante lenta e são dependentes dos eventos meteorológicooceanográficos mais intensos que atingem a Baía de Santos. Essa baía está aberta para o quadrante sul, de onde incidem os ventos e as ondas de maior energia (SW-SSW-S-SSE) geradas pela passagem de sistemas frontais e ciclones extratropicais, que avançam até a região Sudeste do Brasil, vindos do sul da América do Sul. Em condições de tempo bom predominam, na costa paulista, ventos e ondas do quadrante SE-E.

Cúspides praiais de espraiamento foram observadas durante o período de monitoramento praial no setor centro-leste da praia, entre os perfis Góes-02 e Góes04. A partir de 2013 a praia passou a apresentar uma estreita zona de surfe no setor leste, entre os perfis Góes-05 e Góes-04, indicando, portanto, a presença de um banco submerso. Em 2010 e 2011 a praia não apresentava sona de surfe.

Todas essas características e a curvatura acentuada da Praia do Góes definem estados morfodinâmicos variáveis ao longo do arco praial. Por exemplo, na condição atual de ciclo de rotação praial, a porção subaérea da praia exibe características de estado intermediário no setor centro-leste da praia, mas dissipativo de baixa energia no setor oeste (segundo modelos descritos em Short 1999 e Masselink \& Short 1993, e classificação apresentada em Souza 2012). Entretanto, na porção submersa do perfil, as características morfológicas são de estado dissipativo de baixa energia até ultradissipativo. Assim, pode-se definir um estado morfodinâmico "misto", que se encaixa no modelo descrito por Jackson \& Cooper (1984), para uma praia semi-controlada geologicamente pelo embasamento ígneo-metamórfico circundante, e praticamente sem planície costeira. Segundo o modelo, esse tipo de praia recebe pouca contribuição externa de sedimentos e também há pouca fuga de sedimentos. Por essa razão, pode-se supor que ela apresentará um balanço sedimentar com tendência de equilíbrio.

As características climáticas da área de estudo podem ser resumidas a partir dos seguintes dados obtidos junto à estação meteorológica da Ponta da Praia de Santos (Posto E3-070): a temperatura do ar média anual é de $23,8^{\circ}$, com máximas de $32,0^{\circ} \mathrm{C}$ e mínimas de $15,9^{\circ} \mathrm{C}$; embora predomine a calmaria $(52 \%)$, a velocidade média do vento é de $3,5 \mathrm{~m} . \mathrm{s}^{-1}$ (vento moderado na classificação de Beaufort), sendo que os valores médios mais elevados ocorrem entre os meses de novembro a janeiro, com média de $3,9 \mathrm{~m} . \mathrm{s}^{-1}$; a direção predominante dos ventos é de E $(26,0 \%$ das observações), seguida de S $(25,0 \%)$ e SE $(16,7 \%)$; os totais pluviométricos diários, mensais e anuais são elevados, sendo a média anual de 2.151,6 mm, e com $64 \%$ das precipitações ocorrendo no período de primavera-verão (outubro a março) (CODESP/Fundação Ribeiro Franco 2006).

Não há séries históricas de clima de ondas para Santos, mas de acordo com registros do Ministério da Marinha, a altura das ondas que atingem a entrada do Canal de Acesso ao Porto de Santos varia entre 0,4 e 1,9 m (CODESP/Fundação Ribeiro Franco 2006). Dados inéditos obtidos pelo Programa de Modelagem Hidrodinâmica da Área de Descarte do material dragado (localizada em área externa à Baía de Santos, a $20 \mathrm{~m}$ profundidade), realizado para a CODESP, revelaram que no período de 2010-2011 as alturas máximas de ondas atingiram valores entre $5,1 \mathrm{~m}$ (direção SSE) e $0,9 \mathrm{~m}$, com média total de 2,1 m.

$\mathrm{Na}$ costa paulista o regime de marés é semi-diurno com desigualdade diurna. Para Santos, a amplitude da maré é tipicamente de 0,30 m nas marés de quadratura, e de 1,7 m nas marés de sizígia (Harari \& Camargo 1995).

\section{Materiais e Métodos}

A praia subaérea foi monitorada mensalmente por meio de 5 perfis praiais (vide figura 2), no período de janeiro/2010 a dezembro/2011 e de janeiro/2013 a fevereiro/2014 (exceto nos meses de setembro/2011 e agosto/2013).

Os monitoramentos foram realizados em fases de baixamar de maré de quadratura, sendo que, de acordo com a tábua de marés para a região, a amplitude média de variação das marés nesse período foi de $0,25 \mathrm{~m}$. Dadas as carcterísticas morfodinâmicas dessa praia, essa média pouco influencia na variação da largura total da mesma.

Os trabalhos de perfilagem incluíram: levantamento morfométrico do perfil subaéreo da praia até a linha d'água, perpendicular à linha de costa e com realinhamento em cada campanha, sendo mantido fixo apenas o ponto inicial localizado no limite superior da pós-praia (P0); coleta de sedimentos no terço inferior do estirâncio (também visando à identificação de céluals de deriva litorânea segundo o método de Souza 2007); controle georrefernciado dos pontos P0, do limite pós-praia/estirâncio, do local da amostragem e da linha d'água; coleta de dados meteorológicos e do clima de ondas; identificação e monitoramento de indicadores morfológicos, hidrológicos, biológicos e antrópicos de transporte longitudinal (deriva litorânea) e de transporte transversal à praia (costa-adentro e costa-afora) (Souza et al. 2011, 2012a), e de indicadores de erosão costeira (Souza 2009, 2012).

Para analisar as variações morfodinâmicas históricas da praia, verificar a ciclicidade do fenômeno de rotação praial e estabelecer os intervalo de tempo dos ciclos de 
Papel da praia na proteção da costa e as alterações oceanográficas em diferentes escalas temporais

transporte longitudinal, foram efetuadas retroanálises da praia por meio de fotografias aéreas verticais e imagens de satélite de alta resolução para um período de 50 anos, entre 1962 e 2011 (Souza et al. 2012b), apoiadas com fotos de campo obtidas entre 1979 e 2005 por um morador que reside nas proximidades do perfil Góes-04.

De acordo com Short \& Masselink (1999), Short et al. (2000) e Klein et al. (2002), para ciclos de rotação praial mais longos, o comportamento inverso de variação da largura e do volume de sedimentos entre setores opostos da praia, por si só já demonstra o mecanismo de rotação praial, sendo que pode não haver, necessariamente, ganhos ou perdas de sedimentos na praia, ou seja, o balanço sedimentar pode ser próximo do equilíbrio.

Neste trabalho são apresentados gráficos de variação temporal da largura praial obtida para cada perfil de monitoramento, tanto para o período entre janeiro/2010 e fevereiro/2014, como a série histórica de 50 anos.

Gráficos de variação da altura de P0 em relação à linha d'água também foram utilizados para demonstrar os efeitos morfológicos da rotação praial no setor leste da praia, durante os monitoramentos.

O balanço sedimentar foi obtido para as escalas de médio termo, entre 2010 e 2013, e de longo termo, entre 1962 e 2011.

Para ilustrar o balanço sedimentar total da praia em sua condição anual mais construtiva, e mostrar as principais variações morfológicas ao longo do tempo de monitoramento, foram escolhidos os meses de fevereiro de 2010, 2011 e 2013, todos amostrados em situação de tempo bom. O mês de fevereiro/2010 representa o início dos monitoramentos e da rotação praial, e a fase anterior às obras de dragagem de aprofundamento do Canal do Porto; fevereiro/2011 representa a resposta da praia à fase mais pronunciada da rotação praial, ou seja, de transportes no sentido horário e costa-adentro, bem como o período logo após o término das dragagens no trecho da Baía de Santos; fevereiro/2013 corresponde à fase de menor atividade de transporte no sentido horário e de ocorrência de transportes de sentido anti-horário e costa-afora, além de representar o período de acomodação do sistema costeiro decorrido mais de 1 ano após o término das dragagens. Assim, com o auxílio de ferramentas do software Surfer ${ }^{\circledR}$, foram gerados mapas morfológicos interpolados por triangulação, e efetuados os cálculos do volume e do balanço sedimentar da praia, conforme o método descrito em Hanslow (2007).

Ainda, para mostrar as mudanças no balanço sedimentar de cada perfil de monitoramento, e comparar as variações entre eles, foram confeccionados gráficos de variação temporal das médias anuais dos volumes de cada perfil, obtidos para os anos de 2010, 2011 e 2013.

O balanço sedimentar de longo período (50 anos) foi efetuado a partir das fotografias aéreas de 1962, 1972, 1987, 1994 e 2001, e imagens de satélite de 2009 e 2011 (Souza et al. 2012b). Seguindo os métodos descritos em Souza \& Luna (2009, 2010), e com o auxílio de ferramentas do software ArcGis, foi efetuada a delimitação dos polígonos praiais com referência aos limites da pós-praia (praia seca) e a inserção dos alinhamentos dos perfis de monitoramento praial. Posteriormente, foram obtidos os diferentes índices de variabilidade morfodinâmica da praia, incluindo as variações temporais da largura praial em cada perfil, da área e do respectivo volume sedimentar do arco praial, o balanço sedimentar e as respectivas taxas de variação anual.

\section{Resultados e Discussões}

\subsection{O fenômeno de Rotação Praial nos últimos 50 anos}

O fenômeno de rotação praial e sua ciclicidade podem ser observados na escala de 50 anos, entre 1962 e 2011 (figura 3). Nessa figura são identificadas duas condições morfológicas inversas entre si e uma situação intermediária: em 1972 e 2009 a praia apresentava largura máxima no setor oeste e mínima no setor leste; em 1987 e 2011 a situação era inversa; nos demais anos (1962, 1994 e 2011) a praia se encontrava em situações intermediárias.

Em 1972 (dezembro) e 2009 (imagens de junho, após uma ressaca, e de novembro, em condição de tempo bom), a maior progradação no setor oeste e a maior erosão na extremidade leste da praia indicam que ela estava no ápice de um ciclo de transporte longitudinal ou deriva litorânea resultante e predominante para oeste, ou seja, de sentido anti-horário. Como descrito anteriormente, essa é a condição hidrodinâmica mais natural dessa praia.

Nas imagens de 2009, a extrema erosão observada no setor leste da praia é também reflexo da implantação de um muro de arrimo sobre a pós-praia nesse trecho, construído em 2001 e reconstruído em 2005.

Em 1987 e 2011 (julho) a condição morfológica da praia se inverteu em relação a 1972 e 2009, caracterizando uma reorientação da linha de costa e a redistribuição do envelope sedimentar, que passou a apresentar intensa deposição no setor leste da praia e menor a oeste. Portanto, em ambas, a deriva litorânea resultante e predominante passou a ser no sentido horário (de oeste para leste).

Então, tudo indica que de 1972 para 1987 (15 anos) a praia passou de uma fase de pico de transporte de sentido anti-horário, para uma fase de pico de transporte de sentido horário, caracterizando, portanto, a ocorrência do fenômeno de rotação praial.

As situações intermediárias observadas nas demais imagens sugerem fases de instabilidade morfodinâmica, com períodos de transição entre os dois estágios extremos descritos acima.

Em 1962 (março, provavelmente após intensas chuvas) a praia parece estar saindo de uma fase de rotação praial (transporte resultante no sentido horário) e evoluindo no contexto de transporte resultante no sentido anti-horário, cujo ápice é evidenciado na imagem de 1972. 
Papel da praia na proteção da costa e as alterações oceanográficas em diferentes escalas temporais

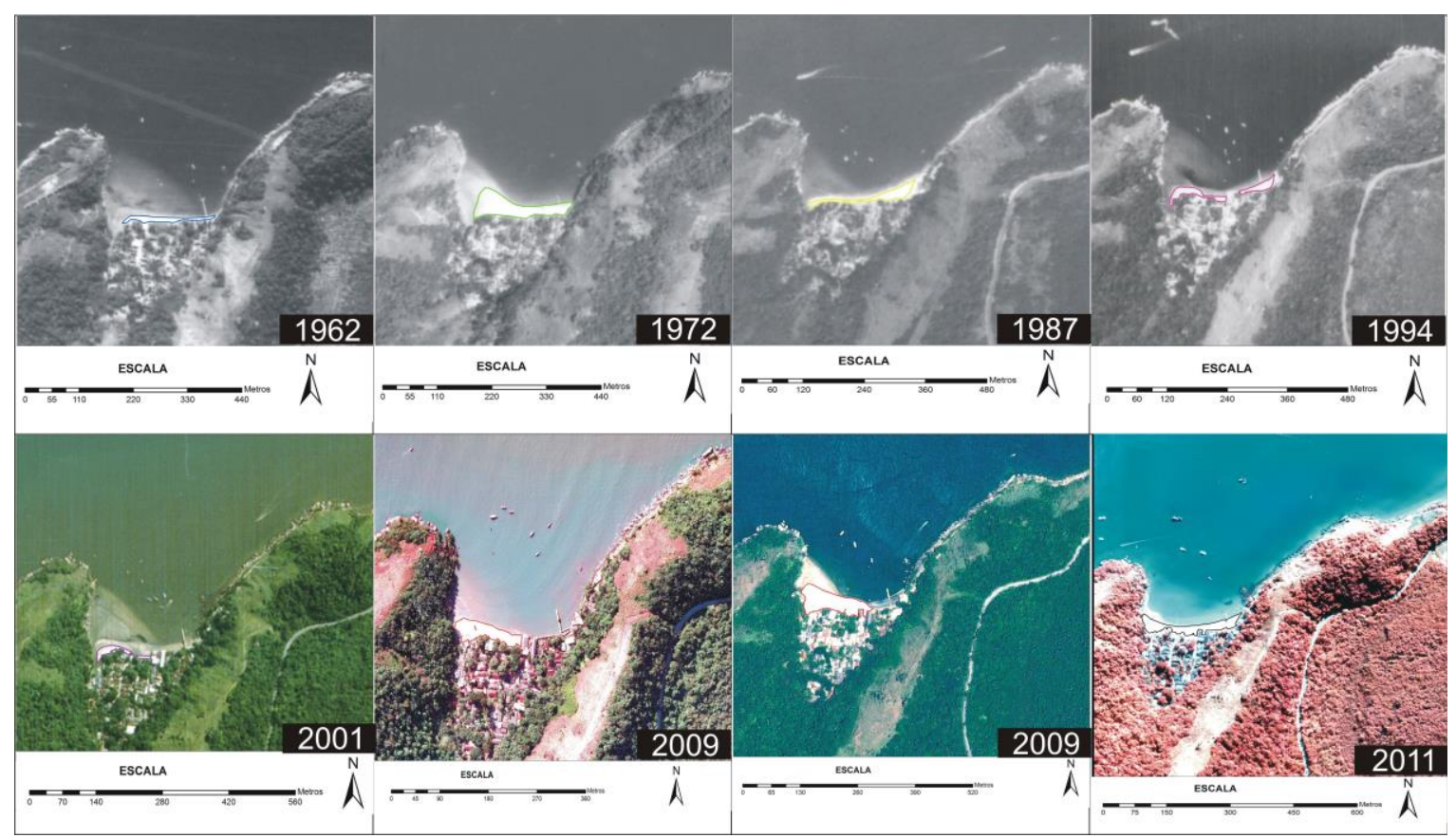

Figura 3: Série histórica de evolução morfodinâmica da Praia do Góes (os polígonos demarcados correspondem à pós-praia). Notar a ausência do píer no setor leste da praia em 1987.

Em 1994 (março), a situação parece se repetir: após o pico da rotação praial evidenciado em 1987, iniciou-se nova fase de reversão no sentido de transporte, para anti-horário, provocando aumento da largura praial no setor oeste e diminuição no setor leste.

Em 2001, apesar da condição bastante erosiva de toda a praia devido à atuação de uma ressaca de forte intensidade que antecedeu o sobrevoo, nota-se a continuidade da evolução da fase de transporte longitudinal de sentido anti-horário observada em 1994. Também é possível depreender que o efeito dessa ressaca foi a erosão acentuada do perfil praial emerso e o transporte de sedimentos para o largo (costa-afora), determinando a formação de um banco subaéreo. É importante ressaltar ainda que a erosão acelerada no setor leste da praia não se deve somente ao ciclo morfodinâmico natural da praia, mas também à implantação do muro de arrimo (proteção contra a erosão) sobre parte da pós-praia entre a extremidade leste e a parte central da praia, naquele ano.

Portanto, o término do último ciclo de transporte anti-horário se deu entre o final/2009 e meados de fevereiro/2010 quando, como comentado anteriormente, após uma ressaca de forte intensidade a direção de transporte se inverteu, dando início ao ciclo atual de rotação praial.

O conjunto de fotos da praia obtidas entre 1979 e 2005 (figura 4), corrobora as discussões acima e auxiliou no detalhamento da cronologia dos eventos.

Entre novembro/1979 e fevereiro/1990 é possível observar que a praia se encontrava em plena fase de transporte de sentido horário, ou seja, em rotação praial, o que é sugerido pela intensa deposição de sedimentos no seu setor leste (perfis Góes-05 e Góes04) e ausência de indicadores de erosão costeira.
Porém, em julho/1992, o setor leste da praia já apresentava vários indicadores de erosão costeira, sugerindo que a inversão no sentido do transporte longitudinal já estava em curso há algum tempo. Em 1994 e 1995 fica claro que o processo erosivo se intensificou sobremaneira.

As fotos de 2005, obtidas após uma ressaca de muito forte intensidade ocorrida no dia 26/abril (segundo os registros históricos, ondas de mais de 3,5 m atingiram o setor leste da Praia de Santos), mostram que o arco praial se deslocou tão intensamente para oeste, que passou a ocupar toda a orla do promontório ocidental da enseada, até quase a sua terminação. Esta foi uma situação anômala e de grande instabilidade morfodinâmica da praia, que pode ter sido condicionada também pelo muro de arrimo existente no setor centro-leste da praia que, aliás, foi reconstruído após essa ressaca.

Em síntese, o primeiro ciclo histórico de rotação praial, já registrado para a Praia do Góes, iniciou-se em alguma data após dezembro/1972 (ápice de transporte de sentido anti-horário) e terminou antes de julho/1992.

De acordo com um levantamento histórico sobre a ocorrência de ressacas na região (Souza et al. 2013), na década de 1970 ocorreram apenas três eventos de forte magnitude, um em 1977 e dois em 1978. Pelas características desses eventos, é mais provável que a ressaca de 17/maio/1977, quando ondas de até 2,5 m atingiram o setor leste da Praia de Santos, tenha desencadeado esse primeiro ciclo de rotação praial. Em relação ao término desse ciclo, sabe-se que entre fevereiro/1990 e julho/1992 ocorreu apenas uma ressaca de forte intensidade, no dia 23/abril/1990, quando ondas de até $2 \mathrm{~m}$ atingiram o setor leste da Praia de Santos. Assim, esse evento pode ser 
Papel da praia na proteção da costa e as alterações oceanográficas em diferentes escalas temporais

considerado como o precursor da nova reversão no sentido de transporte.

Portanto, assumindo essas probabilidades, então o intervalo de tempo de permanência de transporte de sentido horário, ou seja, do ciclo completo do fenômeno de rotação praial, pode ser estimado em 13 anos para essa praia. Este período se encaixa no intervalo determinado pelas duas situações morfológicas extremas e inversas observadas nas fotografias aéreas de 1972 e 1987, e também é próximo ao limite superior estimado por Short \& Trembanis (2004), que determinaram que a oscilação no sentido de transporte de sedimentos em uma praia, assim como a ocorrência de rotação praial, podem variar em escalas de 2 a 10 anos.
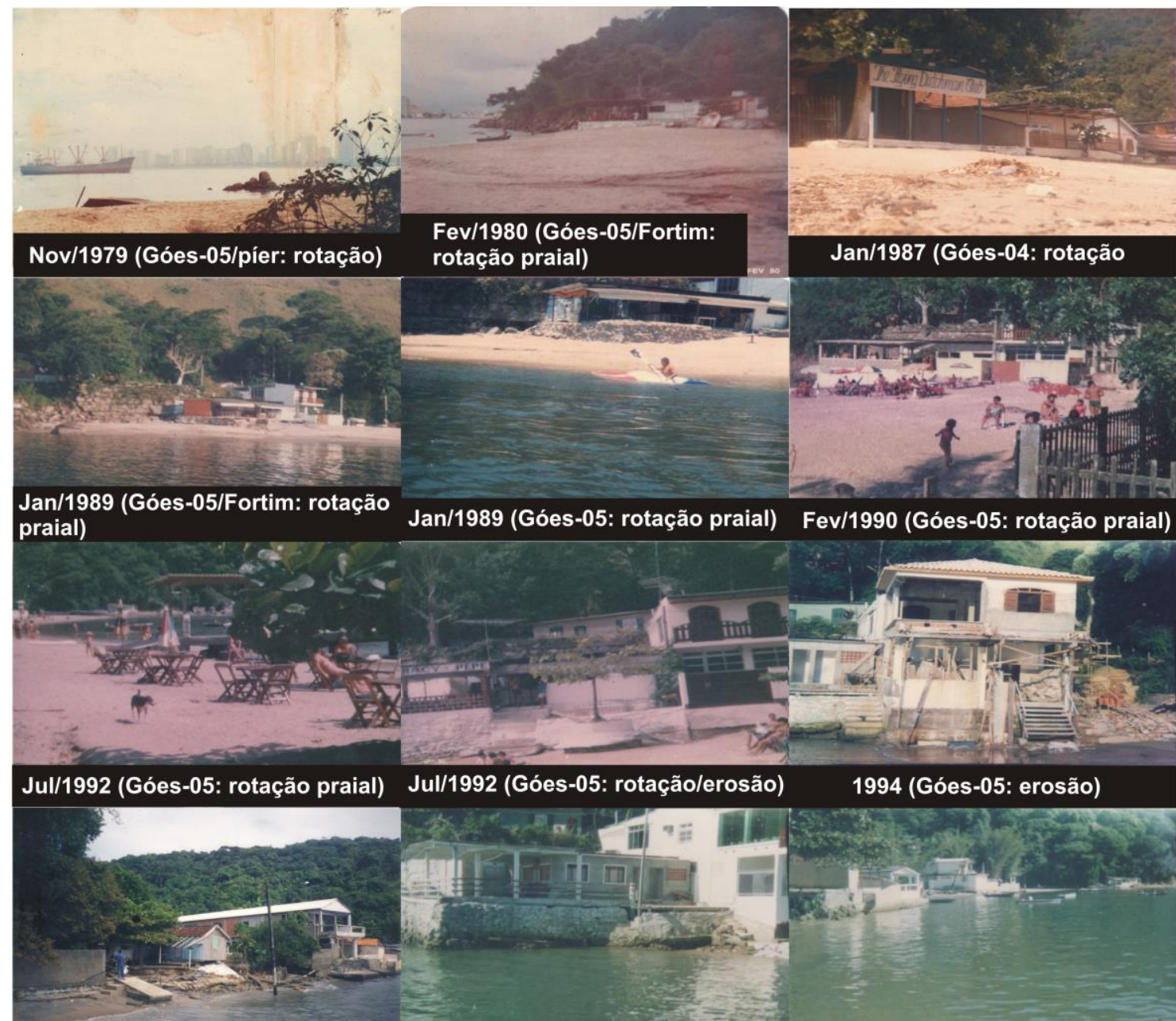

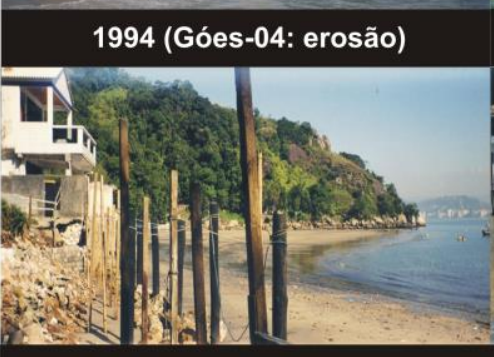

2005 (após a ressaca muito forte de abril: arco praial se estendia até quase a boca da enseada)
Jan/1989 (Góes-05: rotação praial)

Figura 4: Evolução morfodinâmica do setor leste da Praia do Góes durante o penúltimo ciclo de rotação praial (transporte no sentido horário entre 1979 e julho/1992) e na fase de inversão do transporte (sentido anti-horário) até após a ressaca de abril/2005 e a reconstrução do muro de arrimo (fotos: Odair Marcelo, morador local).

Por outro lado, considerando o período entre abril/1990 (final do primeiro ciclo de rotação praial) e fevereiro/2010 (início do ciclo atual de rotação praial), então a duração do ciclo de transporte de sentido antihorário, que reflete a situação mais natural da praia, foi de cerca de 20 anos. Esse intervalo de tempo coincide com o depoimento de alguns antigos moradores da Praia do Góes, ao se referirem à periodicidade com que a faixa de areia da praia "muda de um lado para o outro". 
Papel da praia na proteção da costa e as alterações oceanográficas em diferentes escalas temporais

Finalmente, retroagindo para 1962 (fase intermediária, de transporte anti-horário), então o ciclo de rotação praial que antecedeu essa fase teria se dado entre 1944 e 1957. Registros históricos relatam a ocorrência de fortes ressacas na região entre 1943 e 1946 (Souza 2008), que poderiam estar associadas à evolução desse ciclo.

Como projeção futura, o ciclo atual de rotação praial deverá finalizar em 2023, quando a deriva litorânea resultante passará a predominar novamente no sentido anti-horário. Entretanto, não se pode descartar a possibilidade de diminuição do intervalo de duração desses ciclos, em resposta às alterações advindas das mudanças climáticas globais, afetando a frequência, a intensidade e a magnitude dos eventos meteorológicooceanográficos extremos (e.g. Souza 2010).

A ocorrência desses ciclos pode também ser influenciada por fenômenos climáticos globais, como o ENOS, como identificado por alguns autores (Short et al. 2000, Short \& Trembanis 2004, Anthony et al. 2002, Ranasinghe et al. 2004, Rooney \& Fletcher 2005). No caso do Estado de São Paulo, a sua localização numa zona de transição climática pode mascarar as respostas a tais fenômenos globais. Mesmo assim, é interessante destacar que, de acordo com os registros da ocorrência de El Niño e La Niña (e.g. INPE 2014), todas as situações de inversão de transporte descritas acima coincidem com a atuação de eventos de $E l$ Niño de fraca a forte intensidades, sempre precedidos por fases de La Niña de forte intensidade. Obviamente, a confirmação dessa correlação merece estudos mais detalhados.

\subsection{O fenômeno de Rotação Praial durante o monitoramento}

A figura 5 mostra a sequência temporal dos efeitos da rotação praial no setor leste da Praia do Góes, com destaque ao empilhamento sedimentar rápido e progressivo ocorrido nos primeiros meses de 2010, e à evolução morfológica da praia em comparação aos mesmos meses em 2011 e 2013.

No início dos monitoramentos, em 08/janeiro/2010 (tempo instável), os perfis Góes-04 e Góes-05 não puderam ser levantados pois, mesmo em fase de baixamar, não havia exposição aérea da praia devido à extrema erosão no seu setor leste. A situação morfológica observada se assemelhava muito à exibida na imagem em detalhe da figura 2.

Entretanto, no monitoramento do mês de fevereiro (dia 20, tempo bom), já era possível observar um pequeno empilhamento sedimentar nesse setor da praia, representado pela presença do estirâncio, com largura média de $19,4 \mathrm{~m}$ e declividade média de $3^{\circ}$. Seu limite superior se encontrava na base do muro de arrimo, onde jazia uma zona de deixa de ressaca do mar. Essa mudança morfológica repentina parece marcar o início do fenômeno de rotação praial, cujo provável gatilho foi a frente fria acompanhada de forte ressaca do mar (ondulações de até $2,7 \mathrm{~m}$ e ondas significativas de até 2,0 m; ventos de $\mathrm{S}-\mathrm{SSW}$ de até $8 \mathrm{~m} / \mathrm{s}$ ), que atingiu a região entre os dias anteriores ao monitoramento, entre 17-19/fevereiro. Segundo Harari et al. (2010), esse evento causou uma sobrelevação de nível do mar da ordem de $+0,20$ m na região.

No monitoramento de março (dia 07, tempo bom) o empilhamento sedimentar nesse setor aumentou ainda mais, marcado pelo aparecimento de uma pós-praia com quase 4,0 $\mathrm{m}$ de largura e declividade média de $5^{\circ}$ (máxima de 9,5 em Góes-04). A largura média da praia era de $12,2 \mathrm{~m}$ e havia sobreposição de algumas zonas de deixa de ressacas junto ao muro de arrimo.

Essas três primeiras campanhas de monitoramento foram realizadas antes do início das obras de dragagem de aprofundamento do Canal do Porto, que se deu no final de março/2010 e junto à barra da Baía de Santos. Como citado anteriormente, em frente à Enseada do Góes as dragagens operaram muito pouco e apenas durante setembro-outubro/2010.

Entre os dias 08 (data do monitoramento) e 11/abril/2010, a passagem de uma frente fria acompanhada de ondulações de altura máxima de 5,1 $\mathrm{m}$ e altura significativa de 4,3 m (dia 09) (dados da área de descarte do material dragado), e ventos de S-SSW de até $12 \mathrm{~m} / \mathrm{s}$, desencadearam uma ressaca de muito forte intensidade e maré meteorológica positiva, com sobrelevação do nível do mar de até +0,50 m no dia 08 . Esse evento atingiu a Praia do Góes com ondas de até $2,0 \mathrm{~m}$ (dia 09) e, ao final, havia causando intenso empilhamento sedimentar entre os perfis Góes-05 e Góes-04. O rápido assoreamento no largo e a destruição parcial do píer ali localizado impediram a atração de barcos, fazendo com que a comunidade local ficasse praticamente isolada entre os dias 09 e 11.

Como consequência, na amostragem de maio (tempo bom), a praia entre Góes-04 e Góes-05 já apresentava largura média de quase $15 \mathrm{~m}$, sendo a declividade média da pós-praia de $8,1^{\circ}$ e do estirâncio de $4,7^{\circ}$, demonstrando aumento do empilhamento sedimentar da praia (figura 5).

Entre maio e julho/2010 outras ressacas de menor magnitude se sucederam, dando continuidade ao fenômeno de rotação praial (figura 5).

Nos dias 14-15/agosto/2010, uma nova frente fria acompanhada de ressaca de muito forte intensidade (ondas máximas de $3,5 \mathrm{~m}$ e significativas de $2,8 \mathrm{~m}$; e ventos de até $9,2 \mathrm{~m} / \mathrm{s}$ ) acabou por impor o soterramento completo da ponte de ligação entre o píer e a praia, quando enorme volume de areias foi transportado para o local (figura 5-base), e a erosão do píer aumentou ainda mais.

Nos meses seguintes até dezembro/2010, outras ressacas do mar de média a fraca intensidade contribuíram para a manutenção do empilhamento sedimentar e aumento na declividade e na largura do setor leste da praia, porém com pulsos de transferência de sedimentos de menor magnitude.

Em 2011 ocorreram os últimos grandes pulsos de transporte no sentido horário, desencadeados por duas fortes ressacas em maio. 
Papel da praia na proteção da costa e as alterações oceanográficas em diferentes escalas temporais

A partir de junho/2011 e durante todo o ano de 2012 o processo parece ter desacelerado, pois a praia aparentemente se estabilizou morfodinamicamente.
Todo esse período de tempo foi marcado pela ausência de ressacas importantes.

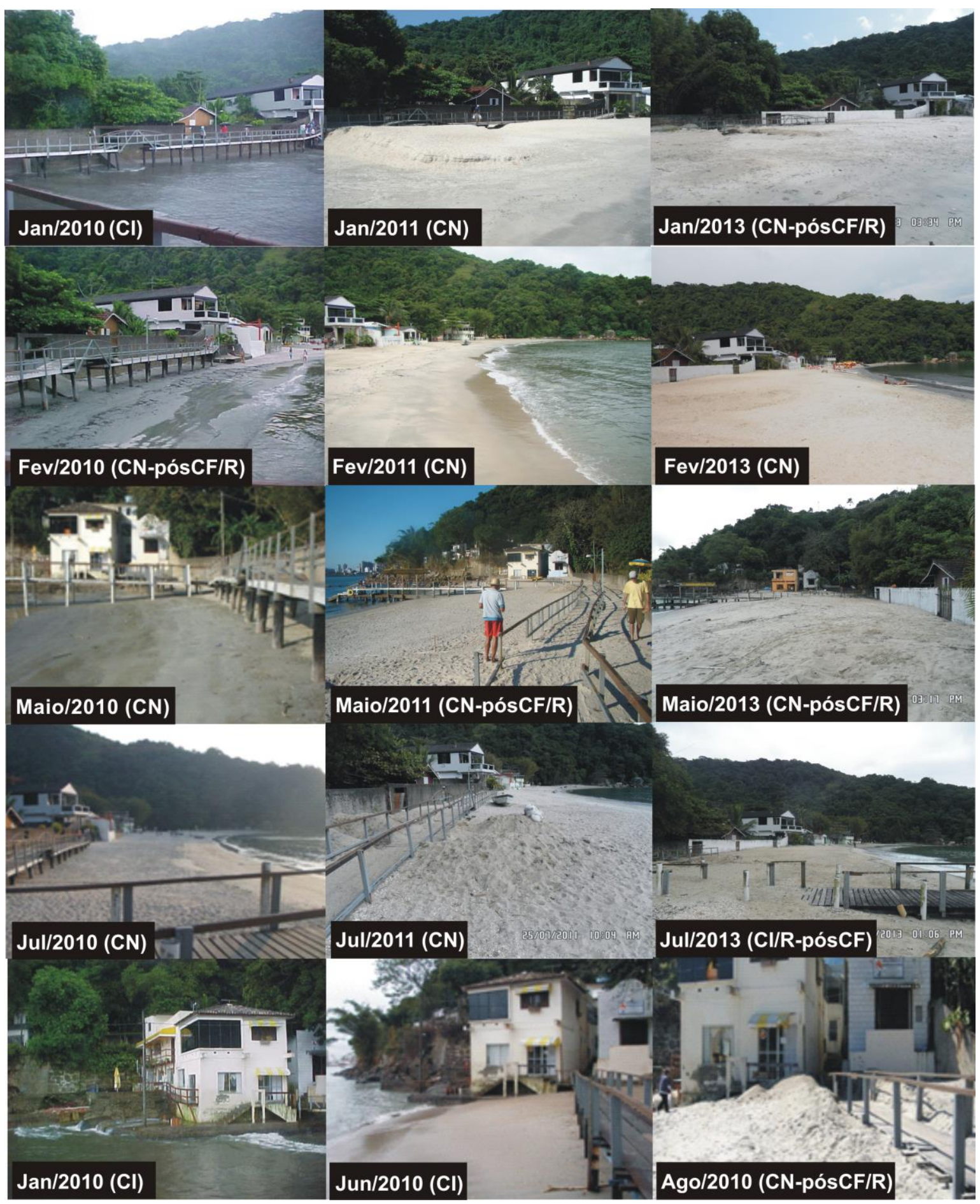

Figura 5: Evolução da rotação praial na área do perfil Góes-04, entre janeiro/2010 (antes) e julho/2013 (processo estabilizado). As três fotos da base mostram o perfil Góes-05 e o Fortim, antes (2010) e durante a fase mais intensa da rotação praial (junho e agosto/2010), com destaque ao intenso empilhamento de areia após a ressaca de agosto/2010. ( $\mathrm{CN}=$ condição de tempo bom; $\mathrm{CF}=$ condição frontal; $\mathrm{Cl}=$ condição intermediária; $\mathrm{R}=$ ressaca) .

Em 2013 ocorreram várias ressacas de fraca e média intensidade e apenas três de forte intensidade (uma em abril e duas em setembro). Entretanto, elas não foram capazes de retomar a evolução do processo de rotação praial nos moldes observados entre fevereiro/2010 e maio/2011, promovendo menor variação morfológica na praia.
As diferenças entre os eventos meteorológicooceanográficos de maior energia de ondas (sistemas frontais e ressacas do mar) que ocorreram nesses anos podem ser a chave para entender a evolução do fenômeno de rotação praial. Em 2010 o número de eventos foi excepcional, desde fevereiro até dezembro, enquanto nos demais anos se restringiram à temporada 
Papel da praia na proteção da costa e as alterações oceanográficas em diferentes escalas temporais

de ressacas do mar (outono-inverno); a magnitude das ressacas foi maior em 2010, com predomínio de eventos de muito forte e forte intensidade durante o ano todo, enquanto em 2011 e 2013 os eventos foram predominantemente de média e fraca intensidade e em menor número, e em 2012 somente de fraca intensidade e raros; em 2010 foi comum a ocorrência de várias ressacas consecutivas ao longo de um mesmo mês, o que não ocorreu nos demais anos; em 2010 e 2011 as ressacas sempre estiveram associadas à passagem de sistemas frontais, mas em 2013 elas ocorreram em geral após a passagem desses sistemas.

A sequência de eventos morfodinâmicos descrita acima indica que a evolução do fenômeno de rotação praial se deu por meio de pulsos controlados por sucessivas ressacas de muito forte a forte intensidades, em especial entre fevereiro/2010 e maio/2011 (18 meses), fase esta que pode ser considerada a mais pronunciada da rotação praial. No decorrer de 2012 e até fevereiro/2014 (final do monitoramento) as evidências sugerem que o fenômeno permaneceu menos ativo e a praia praticamente se estabilizou morfodinamicamente.

O processo de empilhamento de sedimentos no setor leste da praia pode ser mais bem observado por meio das curvas de variação temporal das alturas de P0 em relação à linha d'água nos perfis Góes-04 e Góes-05 (figura 6). Nesse trecho a altura inicial do perfil sofreu uma elevação média total de 3,10 m entre janeiro/2010 e fevereiro/2014.

Os mecanismos responsáveis por esse empilhamento sedimentar foram os intensos transportes longitudinais de sentido horário, associados aos transportes costaadentro, gerados durante as ressacas do mar na fase mais pronunciada da rotação praial, entre fevereiro/2010 e maio/2011. Nessa época, as ressacas promoviam um aumento significativo na altura da praia, comportamento este contrário ao que é normalmente esperado durante esses eventos. Entretanto, a partir de agosto/2011, esse comportamento se inverteu, pois a altura da praia passou a diminuir durante as ressacas, sugerindo, como esperado, erosão do envelope praial e o transporte de sedimentos costa-afora.

Outro fato que também sugere essa mudança nos mecanismos de transporte e, aliás, é consequência dela, foi o aparecimento de uma zona de surfe no setor leste da praia em 2013, até então inexistente (figura 7). Sua presença indica um reafeiçoamento no perfil praial em função de transporte costa-afora e da formação de um banco arenoso submerso.

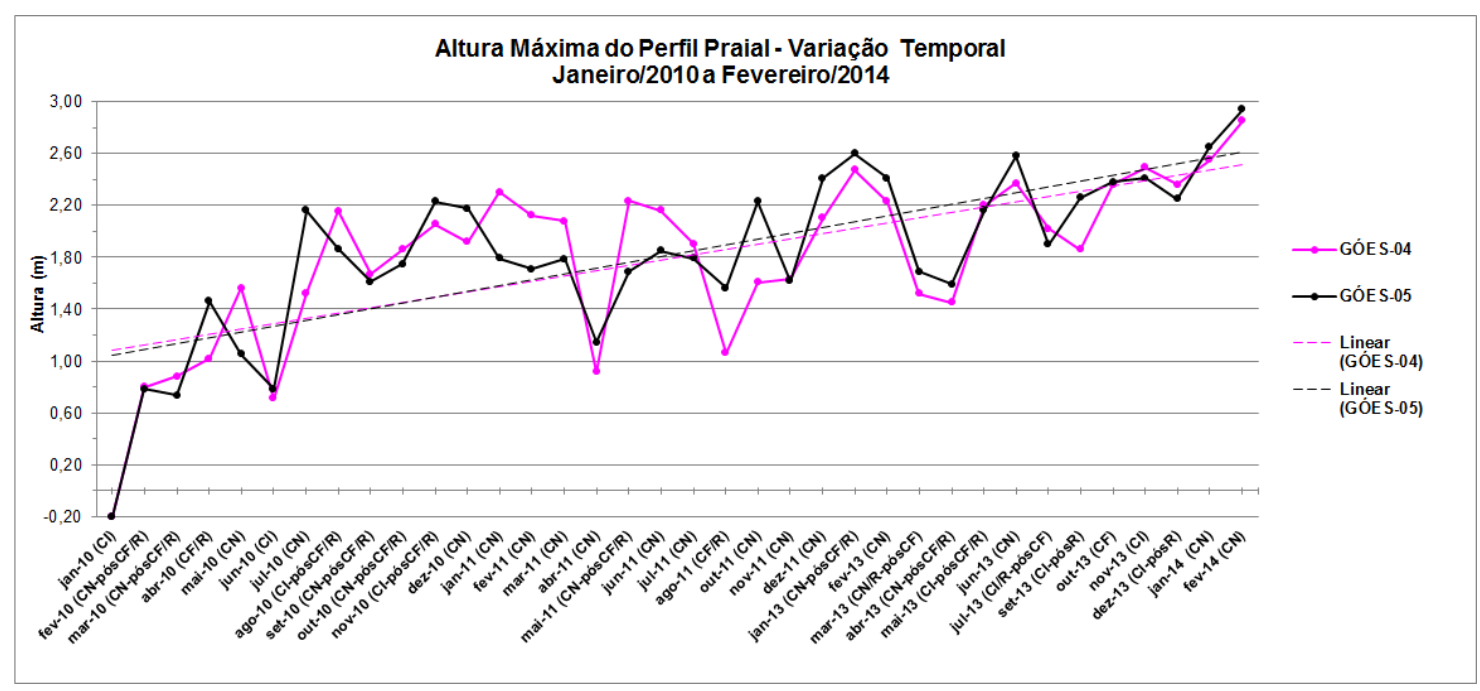

Figura 6: Evolução da altura da praia e linhas de tendência nos perfis Góes-04 e Góes-05 no período de janeiro/2010 a fevereiro/2014 (CN=tempo bom; $\mathrm{CF}=$ condição frontal; $\mathrm{CI}=$ condição intermediária; $\mathrm{R}=$ ressaca).

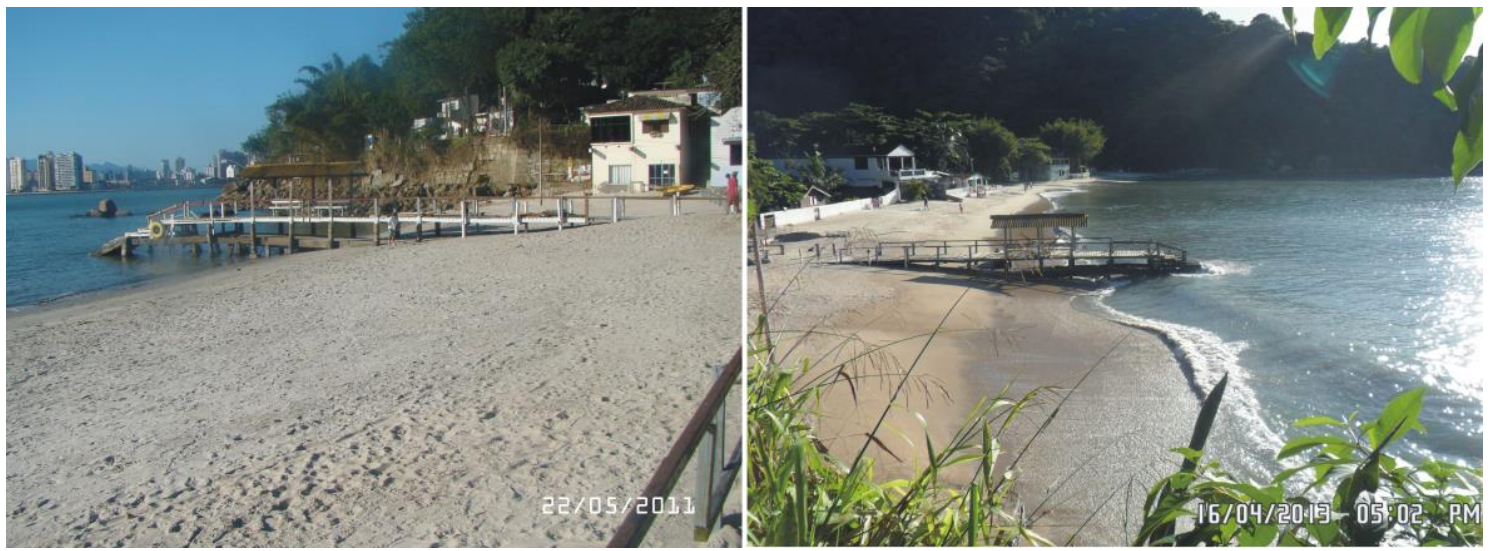

Figura 7: Setor leste da Praia do Góes: ausência de zona de surfe em 2011 e presença da mesma em 2013 (ambas as fotos obtidas nas mesmas condições de maré e de tempo bom, e após a atuação de uma ressaca). 
Papel da praia na proteção da costa e as alterações oceanográficas em diferentes escalas temporais

Por outro lado, o resultado morfológico desse empilhamento sedimentar não foi derivado apenas do fenômeno da rotação praial, mas também foi influenciado pela presença do muro de arrimo sobre a pós-praia, que impede a acomodação natural dos sedimentos e a suavização do perfil. Neste sentido, esse muro parece estar afetando a resposta morfológica do setor centro-leste da praia aos dois ciclos de transporte costeiro, desde a sua implantação em 2001, a saber: (a) acelerou a erosão do setor leste da praia no período entre 2001 e 2009, alterando o realinhamento da linha de costa em relação ao padrão observado em 1972; (b) contribuiu para os efeitos da grande ressaca de 2005, forçando, de maneira anômala, o deslocamento de todo o envelope praial para oeste, que passou a ocupar toda a zona de sombra até a boca da Enseada do Góes; (c) modificou a redistribuição do envelope praial durante o ciclo atual de rotação praial, resultando em um realinhamento da linha de costa diferente do observado em 1987; (d) produziu um empilhamento de sedimentos de altura anômala no setor centro-leste da praia, forçados pelo menor espaço disponível para sua acomodação.

\subsection{Variação temporal da largura praial de médio e longo termo}

Durante os monitoramentos o comportamento da largura praial seguiu tendências inversas entre os setores opostos da praia, corroborando o esperado para o fenômeno de rotação praial (figura 8). Obviamente, devem ser levadas em consideração as influências das condições meteorológico-oceanográficas amostradas, que podem afetar de várias formas as larguras medidas.

Os perfis Góes-01 e Góes-05, localizados nas extremidades opostas da praia, apresentaram variações inversas e mais acentuadas (linhas de tendência mais inclinadas) que os demais, em especial durante a fase mais proeminente da rotação praial ao longo de 2010: Góes-05 passou de $0,0 \mathrm{~m}$ em janeiro para 28,50 m em dezembro, enquanto Góes-01 passou de 51,90 m para 43,20 m no mesmo intervalo de tempo.

Nesse mesmo período os perfis intermediários Góes02 e Góes-04 também seguiram tendências inversas entre si, acompanhando os seus vizinhos das terminações da praia, porém com variações menores (linhas de tendência com menor inclinação). O perfil Góes-03 apresentou uma linha de tendência quase horizontal, com variações de pequena amplitude, como esperado para o ponto pivô de uma praia em rotação praial. A suave tendência de diminuição temporal de largura pode estar relacionada à interferência direta do muro de arrimo, cuja terminação está a poucos metros a leste desse perfil.

Em 2011 as tendências de todos os perfis continuaram as mesmas, porém de maneira menos acentuada. As mudanças mais significativas ocorreram nos perfis Góes-5 (cada vez mais largo que Góes-04 e Góes-03) e Góes-02 (cada vez mais estreito que os demais). Em Góes-4 e Góes-3 as larguras se aproximaram entre si. O perfil Góes-01 se comportou de maneira irregular, embora com tendência resultante de redução geral de largura.

Ao longo de 2013 até fevereiro/2014 a largura de Góes-05 se aproximou da de Góes-01 e até chegou a ultrapassá-la em janeiro e abril/2013; Góes-02 sofreu maior variabilidade e se manteve bem mais curto que os demais perfis, embora com menor taxa de redução de largura que anteriormente; as larguras de Góes-04 e Góes-03 se igualaram a partir de julho/2013.

A condição geral de Góes-02, como perfil mais estreito da praia desde novembro/2010, está associada à presença de um embaíamento (curvatura acentuada da praia) que se formou nessa área entre setembrooutubro/2010, provavelmente devido a um controle forçado pelas ondas durante o processo de rotação praial. Isto resultou no estabelecimento de uma zona de divergência de células de deriva litorânea quase que permanente nesse local, conforme indicam os estudos (inéditos) sobre a circulação das células de deriva litorânea realizados na praia. Em outras palavras, esse perfil passou a ser fonte de sedimentos para os seus vizinhos. Isto demonstra que, mesmo num ciclo de um sentido de transporte longitudinal, podem coexistir células de deriva litorânea de sentidos opostos, e até mesmo ocorrer uma resultante temporária com sentido oposto à tendência geral de transporte, regulando os processos sedimentares ao longo do arco praial. Isto pode explicar o comportamento irregular de Góes-01 e também porque a redução de largura nele não foi tão proeminente quanto o aumento observado em Góes-05.

Em relação às variações ocorridas em longo termo, entre 1962 e 2011 (figura 9; vide também figura 3), o comportamento das larguras dos perfis (pós-praia) é compatível com o esperado dentro de cada ciclo de transporte longitudinal.

O perfil Góes-01 apresenta uma variabilidade muito influenciada pela migração lateral de um córrego que desemboca no extremo oeste da praia, e que acabou determinando valores "nulos" de largura da pós-praia na maioria dos anos. Entretanto, nos períodos de predomínio de transporte de sentido anti-horário, como em 1972 e 2009, as tendências das curvas indicam que as larguras no setor oeste da praia, incluindo o perfil Góes-02, são destacadamente maiores que no restante dela. A mesma tendência pode ser observada para os anos de 1962, 1994 e 2001 (ciclos de transporte antihorário após fases de rotação praial/transporte de sentido horário). Portanto, pode-se considerar que apenas durante o pico da rotação praial, em 1987, a largura do extremo oeste da praia teria sido de fato mínima ou nula.

No outro extremo da praia, os perfis Góes-05 e Góes04 seguem comportamentos mais regulares e compatíveis com os ciclos de transporte, apresentando larguras maiores nas fases mais acentuadas de rotação praial (transporte horário), como em 1987 e 2011, e mínimas nos ciclos de transporte anti-horário. A extrema erosão observada em 2001 e 2009 (valores nulos) parece ter sido influenciada também pelo muro de arrimo nesse trecho da praia. 
Papel da praia na proteção da costa e as alterações oceanográficas em diferentes escalas temporais

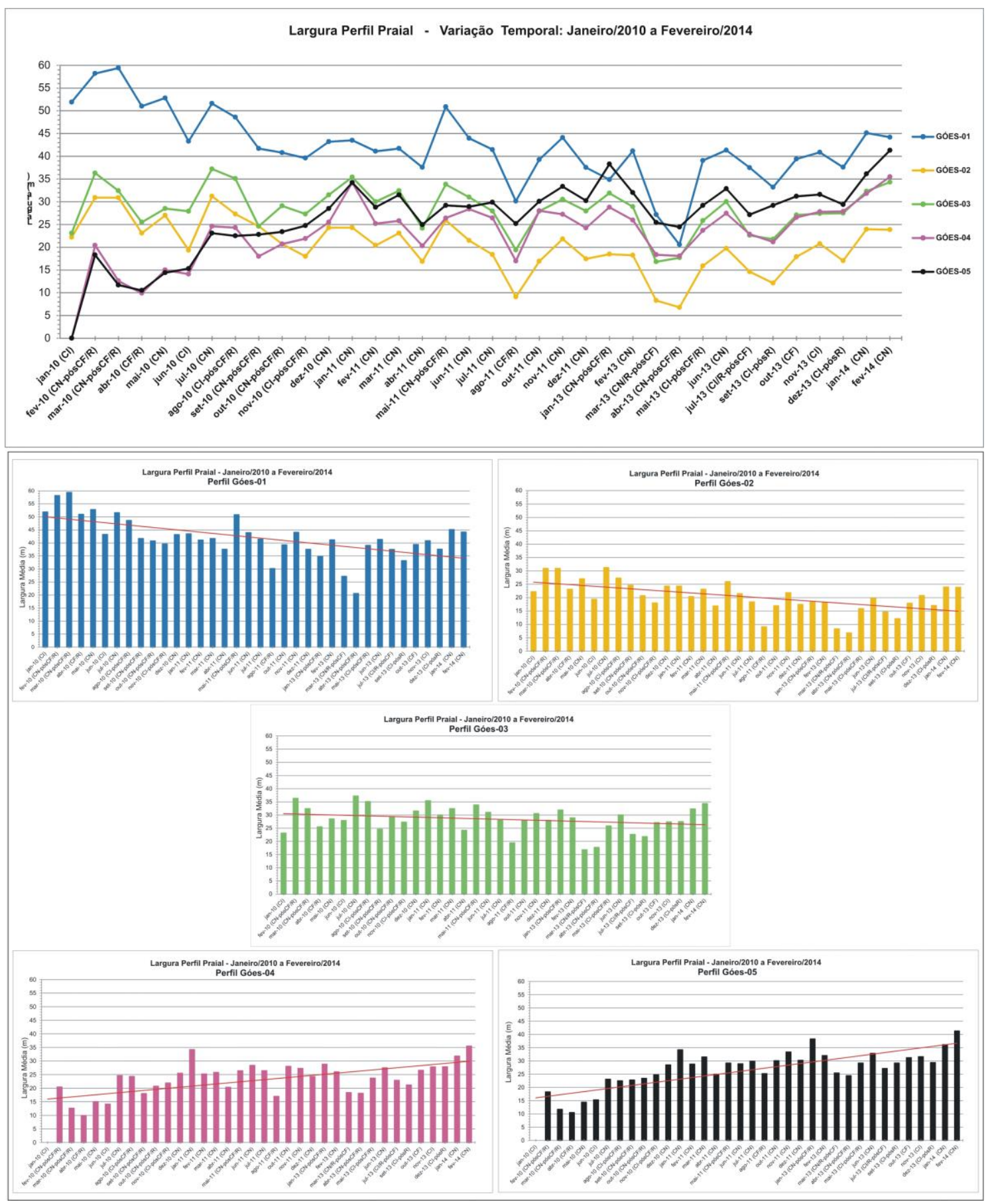

Figura 8: Evolução temporal da largura praial e linha de tendência para cada perfil monitorado, no período de janeiro/2010 a fevereiro/2014. ( $\mathrm{CN}=$ tempo bom; $\mathrm{CF}=$ condição frontal; $\mathrm{CI}=$ condição intermediária; $\mathrm{R}=$ ressaca).

As taxas médias de variação da linha de costa de longo período foram positivas para quase todos os perfis, mostrando tendências suaves de acreção de longo termo, com valores menores e próximos entre si em Góes-04 (2,38 m) e Góes-03 (2,47 m), e maiores em Góes-01 (5,57 m) e Góes-05 (3,37 m) (Souza et al. 2012b).

Em Góes-02, a taxa média ligeiramente negativa ($0,44 \mathrm{~m})$ pode até ser considerada nula. Esse comportamento, junto com as diferenças observadas entre Góes-01 e Góes-05, pode estar relacionado à presença pretérita do centro de divergência de células de deriva litorânea em Góes-02, assim observado durante os monitoramentos. Por outro lado, esse resultado levanta uma hipótese de que no passado esse local poderia ter sido o ponto pivô da praia, ao invés de Góes-03.

No cômputo final para os 50 anos, a taxa média de variação da largura da pós-praia em toda a praia foi de +2,67 m, o que corresponde a uma variação linear média da linha de costa de $+0,05 \mathrm{~m} / \mathrm{ano}$, que pode ser considerada nula ou em equilíbrio. Esse resultado, por si só, indica que as variações observadas nessa praia foram devidas essencialmente à ocorrência dos ciclos de transporte. 
Papel da praia na proteção da costa e as alterações oceanográficas em diferentes escalas temporais

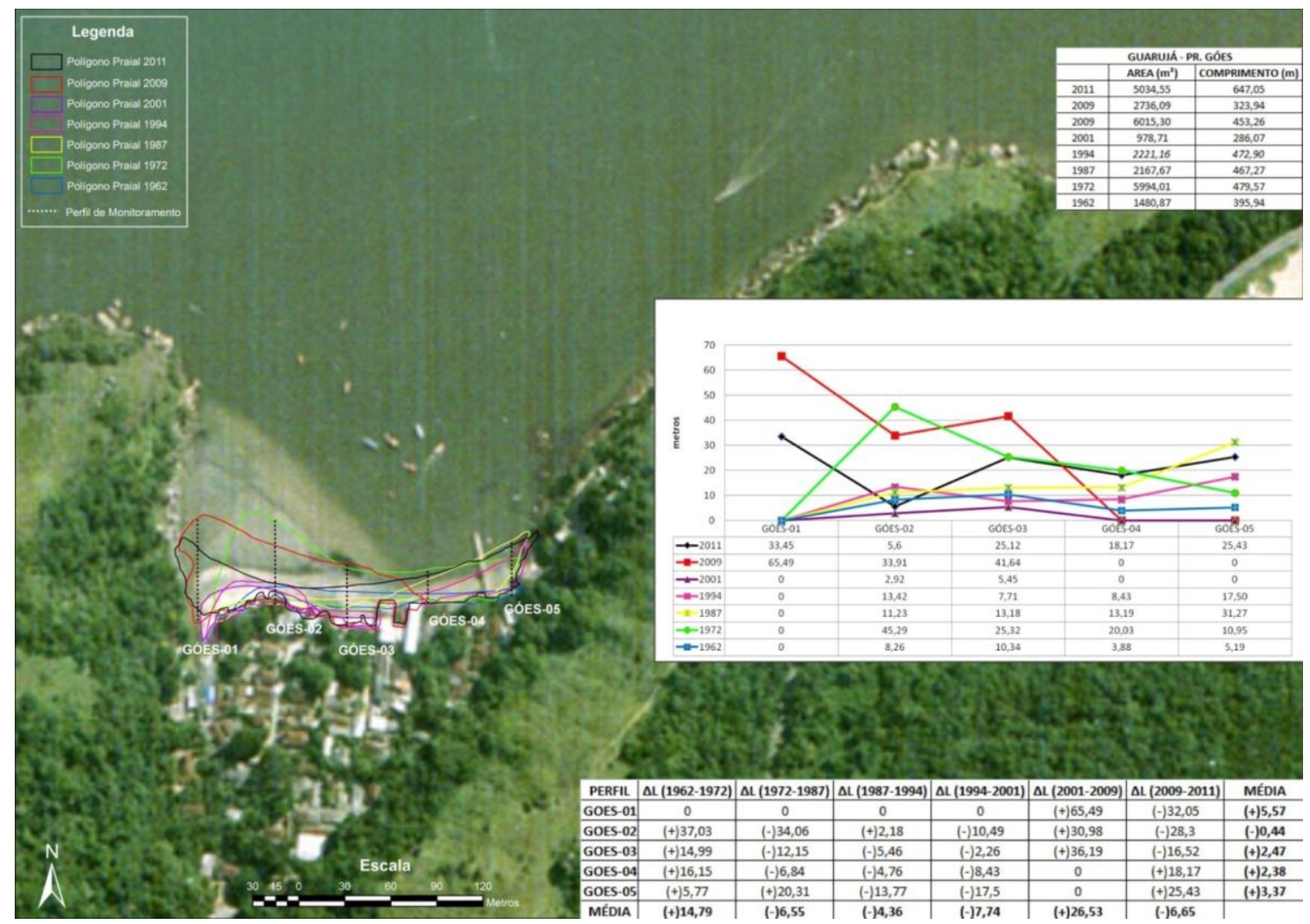

Figura 9: Variação da linha de costa da Praia do Góes entre 1962 e 2011 ( $\Delta \mathrm{L}$ = variação de largura da pós-praia). As linhas coloridas representam os polígonos de contorno da pós-praia em cada ano.

Finalmente, comparando as médias das larguras da pós-praia obtidas nos três anos de monitoramento e a média da série histórica de 1962-2011, observam-se curvas sintônicas entre si, ou seja, que os perfis seguem as mesmas tendências ao longo do tempo (figura 10). A curva de 1962-2011 é idêntica à de 2010 para o trecho entre os perfis Góes-03 e Góes-05, mas as larguras são maiores que as demais curvas no setor oeste da praia (Góes-01 e Góes-02). Esta tendência é esperada e enfatiza a resposta à defasagem temporal entre os dois ciclos de transporte, já que o ciclo de sentido antihorário (estado mais natural da praia), por ser mais longo que o de sentido horário (rotação praial), influenciou sobremaneira a curva histórica, e a curva de 2010 retrata o início da rotação praial após uma longa fase de transporte no sentido anti-horário.

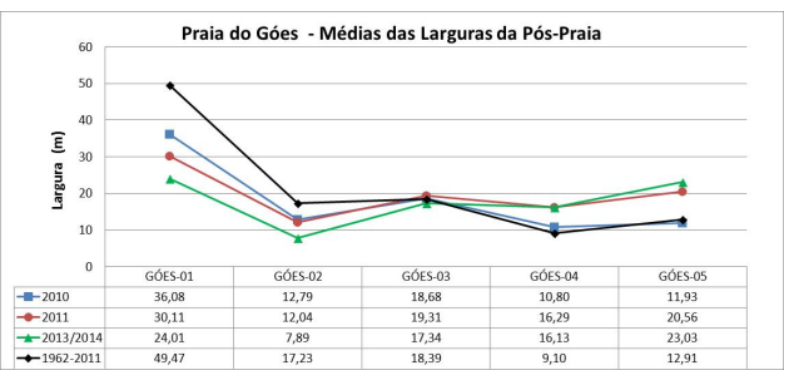

Figura 10: Variação espaço-temporal das médias das larguras da póspraia para os anos de monitoramento e a série histórica.

A sequência temporal exibida pelas curvas de 2010, 2011 e 2013/2014 mostra, com maior clareza, a evolução esperada durante a fase de rotação praial, caracterizada pelo basculamento das curvas em torno de um eixo central coincidente com o ponto pivô da praia (perfil Góes-03), que exibiu variabilidade temporal desprezível. Isto parece anular a hipótese de Góes-02 ter sido ponto pivô no passado.

Esses resultados reafirmam o caráter natural dos processos atuais, que apresentam um padrão evolutivo muito semelhante ao pretérito.

\subsection{Variação temporal do diâmetro médio dos sedimentos durante o monitoramento}

A variabilidade temporal das granulometria dos sedimentos de uma praia em rotação praial pode ou não ser utilizada como um indicador desse fenômeno.

No caso da área de estudo, esse parâmetro é importante, por três razões: a praia é semi-controlada geologicamente pelo embasamento circundante (segundo o modelo descrito em Jackson \& Cooper 1984); não há praias muito próximas que possam contribuir como fontes externas de areias; a zona de sombra no setor ocidental da enseada acondiciona grande quantidade de areias durante a fase de transporte no sentido anti-horário, que ali vão se acumulando seletivamente ao longo do tempo, e parte dessas areias são transferidas para o lado oposto durante a rotação praial.

De fato, durante os monitoramentos as características texturais dos sedimentos se alteraram paulatinamente em toda a praia, em especial o diâmetro médio das areias (figura 11). De maneira geral, de janeiro/2010 até dezembro/2010, à medida que a rotação praial evoluía mais intensamente, as areias foram se tornando 
Papel da praia na proteção da costa e as alterações oceanográficas em diferentes escalas temporais

relativamente mais finas, na seguinte sequência: antes da rotação praial e até seus primeiros pulsos, entre janeiro-março/2010, elas eram predominantemente grossas; entre abril-junho/2010 passaram a dominantemente médias; entre julho/2010-julho/2011 se tornaram finas; e entre novembro-dezembro/2011 passaram a muito finas. No decorrer de 2013 as areias continuaram predominantemente finas, e nos dois primeiros meses de 2014 passaram a muito finas.

Durante 2010-2011, o predomínio de areias finas em toda a praia parece marcar a fase de maior transferência dos sedimentos que estavam aprisionados no perfil submerso do setor ocidental da enseada (zona de sombra), para o setor leste (transporte longitudinal + transporte costa-adentro). Por outro lado, o ressurgimento de areias médias e grossas na praia em agosto/2011 e entre março e maio e em setembro de 2013, sempre associado à atuação de ressacas, sugere que durante esses eventos passou a predominar erosão na pós-praia (presença de areias grossas e cascalhos biodetríticos depositados em ressacas antigas) e transporte costa-afora. Portanto, aqui também fica caracterizada a mudança no padrão dos processos sedimentares desde meados de 2011, conforme discutido anteriormente.

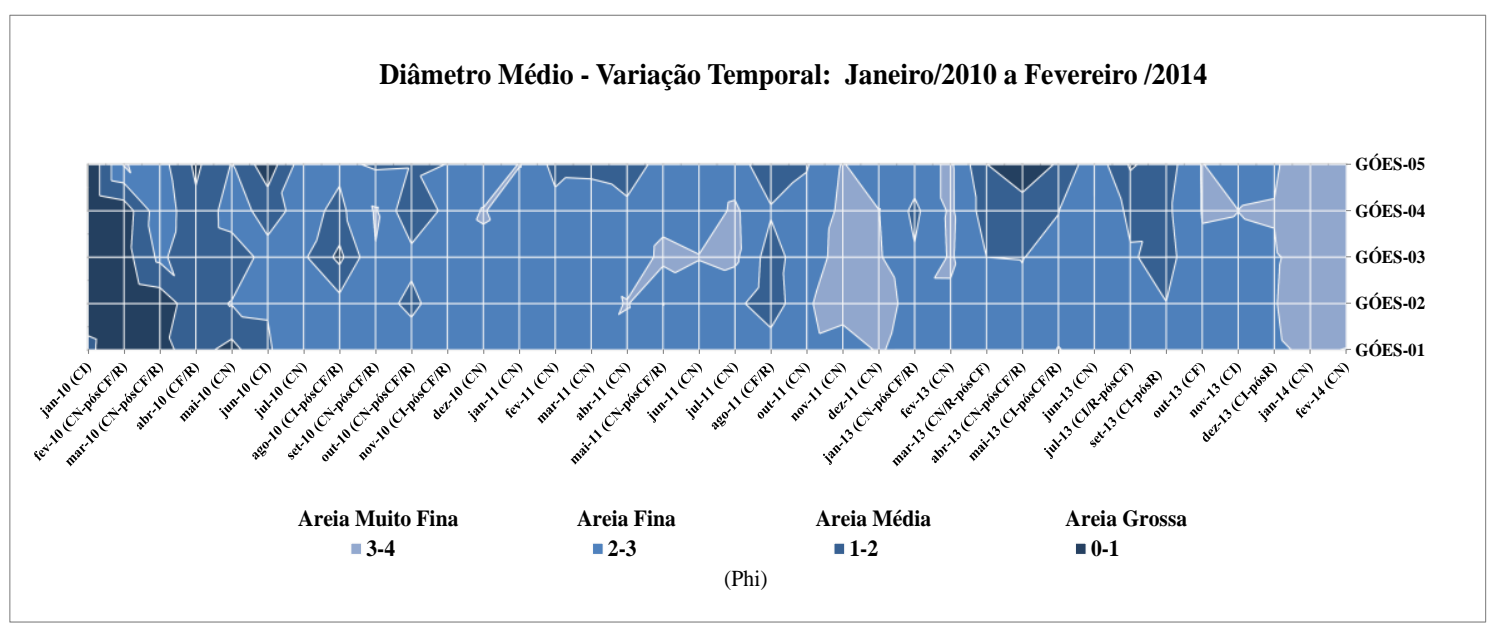

Figura 11: Evolução temporal do diâmetro médio dos sedimentos do estirâncio (valores interpolados) no período de janeiro/2010 a fevereiro/2014. ( $\mathrm{CN}=$ tempo bom; $\mathrm{CF}=$ condição frontal; $\mathrm{Cl}=$ condição intermediária; $\mathrm{R}=$ ressaca).

A presença de areias muito finas em toda a praia no final de 2011 e início de 2014 esteve relacionada à permanência de condições de tempo bom (Anticiclone) por períodos muito prolongados.

\subsection{Balanço sedimentar da praia durante o monitoramento}

A figura 12 exibe as representações morfodinâmicas da praia obtidas para os meses de fevereiro de 2010 (início da rotação praial), 2011 e 2013.

Os mapas de 2010 e 2011 mostram situações altimétricas inversas e características da rotação praial: em fevereiro/2010 as maiores alturas se encontravam no setor oeste da praia e as menores no setor leste; em fevereiro/2011 verfica-se uma situação contrária. Em 2013, por outro lado, a distribuição altimétrica se mostra bastante homogênea ao longo de todo o arco praial.

Assim, esses mapas indicam três fases morfodinâmicas distintas: início da rotação praial em 2010; rotação praial efetivada (transporte longitudinal de sentido horário e transporte costa-adentro) em 2011; reajuste morfológico e mais equilibrado do perfil praial em 2013, provavelemente orientado pela atuação importante de correntes de deriva litorânea para oeste e de transportes costa-afora.

Os volumes obtidos para 2010, 2011 e 2013 são muito próximos entre si, sendo o balanço sedimentar de
$265,80 \mathrm{~m}^{3}$, que representa menos do que $5 \%$ do volume inicial, indicando, portanto, balanço sedimentar em equilíbrio (figura 13). Esses resultados corroboram o comportamento esperado para uma praia sob controle geológico em rotação praial.

Em relação ao balanço sedimentar de cada perfil de monitoramento, entre 2010 e 2013 verificam-se tendências inversas de variação do volume entre os setores opostos da praia (figura 14). No setor oeste da praia (perfis Góes-01 e Góes-02) o balanço sedimentar foi progressivamente negativo ao longo do tempo, enquanto que no setor leste (Góes-04 e Góes-05) foi progressivamente positivo, porém em taxas mais acentuadas que no setor oeste. A variabilidade foi muito baixa em Góes-03 (ponto pivô).

Esses resultados também corroboram com os esperados para uma praia em rotação praial.

\subsection{Balanço sedimentar da praia de longo termo}

As variações temporais de área e de volume do polígono praial (pós-praia) para a série histórica entre 1962 e 2011, como tudo nessa praia, são condicionadas pelos ciclos de transportes de sentido horário (rotação praial) e anti-horário (condição natural da praia), bem como pelas condições meteorológico-oceanográficas antecedentes a cada sobrevoo. 
Papel da praia na proteção da costa e as alterações oceanográficas em diferentes escalas temporais

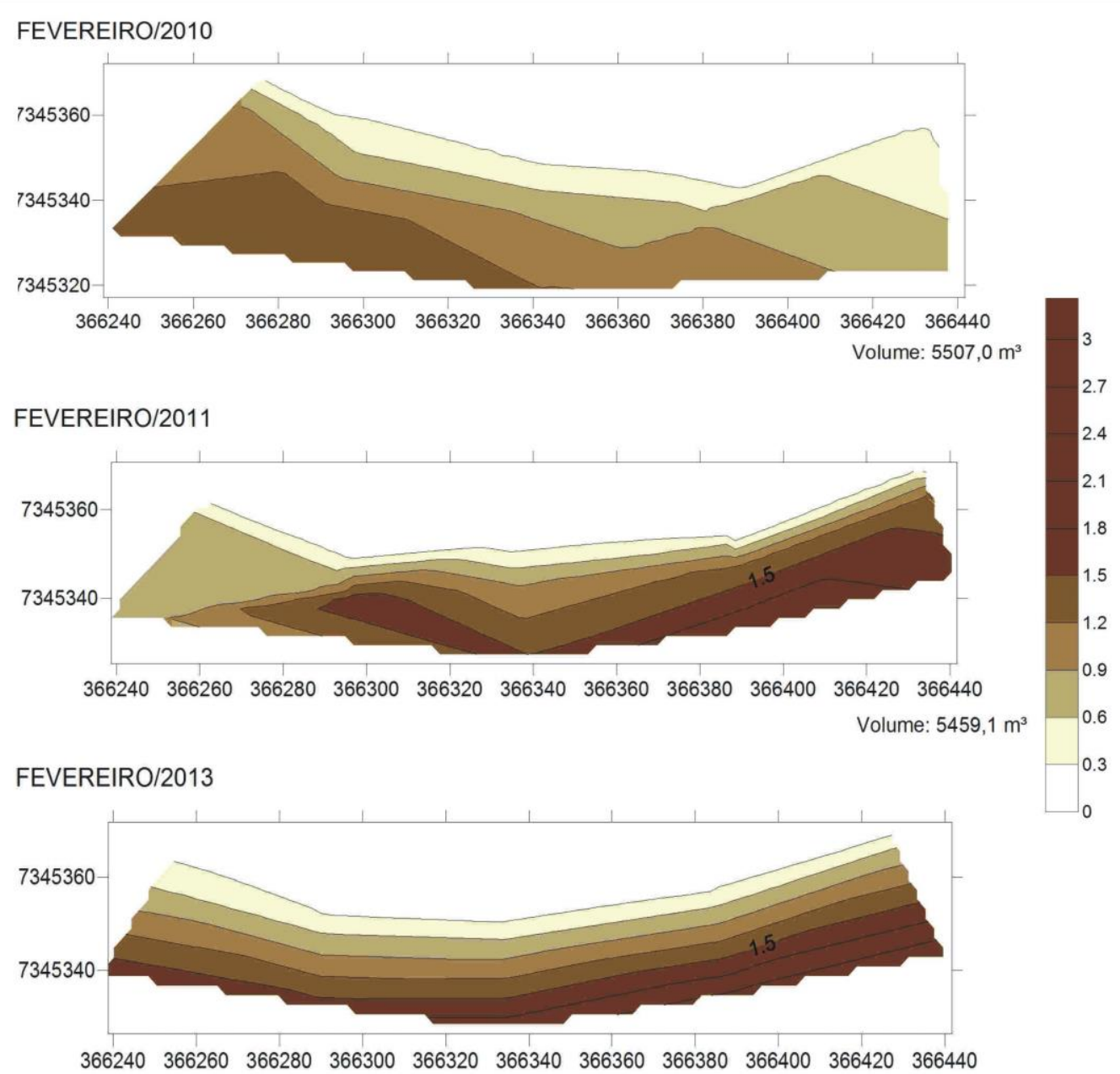

Volume: $5772,8 \mathrm{~m}^{3}$

Figura 12: Representação morfodinâmica e volume sedimentar nos meses de fevereiro de 2010, 2011 e 2013.

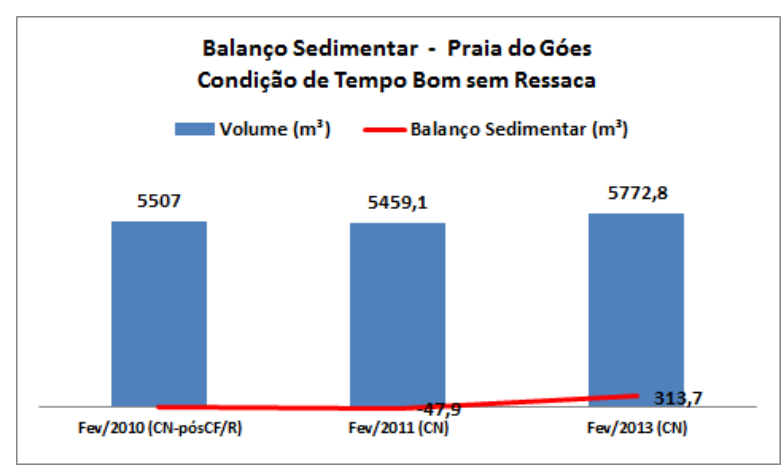

Figura 13: Balanço sedimentar da praia nos meses de fevereiro de 2010, 2011 e 2013.

As maiores áreas e, consequentemente, os maiores volumes, correspondem aos dois anos de pico de transporte de sentido anti-horário, 1972 e 2009 (tabela 1). Os valores muito próximos entre si para cada um dos parâmetros indicam que essa é, de fato, a condição mais natural e equilibrada para essa praia.

A menor área e o menor volume foram obtidos em 2001, pois, como comentado anteriormente, a imagem foi obtida após a atuação de uma ressaca de forte intensidade, que erodiu muito o perfil praial e remanejou os sedimentos para o largo.

Tabela 1: Variação temporal da área da pós-praia e balanço sedimentar de longo termo.

\begin{tabular}{cccc}
\hline ANO & ÁREA $\left(\mathbf{m}^{2}\right)$ & VOLUME $\left(\mathbf{m}^{\mathbf{3}}\right)$ & $\begin{array}{c}\Delta \text { VOLUME } \\
\left(\mathbf{m}^{\mathbf{3}}\right)\end{array}$ \\
\hline $\mathbf{1 9 6 2}$ & 1480,87 & 3035,78 \\
$\mathbf{1 9 7 2}$ & 5994,01 & 12287,72 & 9251,94 \\
$\mathbf{1 9 8 7}$ & 2167,67 & 4443,72 & $-7844,00$ \\
$\mathbf{1 9 9 4}$ & 2221,16 & 4553,39 & 109,67 \\
$\mathbf{2 0 0 1}$ & 978,71 & 2006,35 & $-2547,04$ \\
$\mathbf{2 0 0 9}$ & 6015,30 & 12331,36 & 10325,01 \\
$\mathbf{2 0 1 1}$ & 5034,55 & 10320,83 & $-2010,53$ \\
\cline { 2 - 4 } & \multicolumn{2}{c}{ BALANÇO SEDIMENTAR } & $\mathbf{7 2 8 5 , 0 5}$ \\
\hline
\end{tabular}

No cômputo dos 50 anos observa-se um incremento em área de cerca de $3.554 \mathrm{~m}^{2}$, ou uma taxa de aumento de $71 \mathrm{~m}^{2} /$ ano.

Em relação ao balanço sedimentar de longo termo, fica evidente que a praia apresentou maiores saldos de volume nos anos de pico do transporte de sentido antihorário. A maior perda de volume ocorreu no intervalo de 1972-1987, exatamente quando a praia passou da situação de maior estabilidade (transporte anti-horário) para a de maior instabilidade (transporte horário ou 
Papel da praia na proteção da costa e as alterações oceanográficas em diferentes escalas temporais

rotação praial), ou seja, sofreu completa reorientação da linha de costa. Outro déficit de sedimentos ocorreu recentemente, entre 2009 e $2011\left(-2010,5 \mathrm{~m}^{3}\right)$, como efeito da própria rotação praial e do rápido realinhamento da linha de costa. Nos demais períodos ocorreram intercalações entre ganhos (1962-1972, 1987-1994) e perdas (1994-2001) de volume, em taxas bastante variadas.

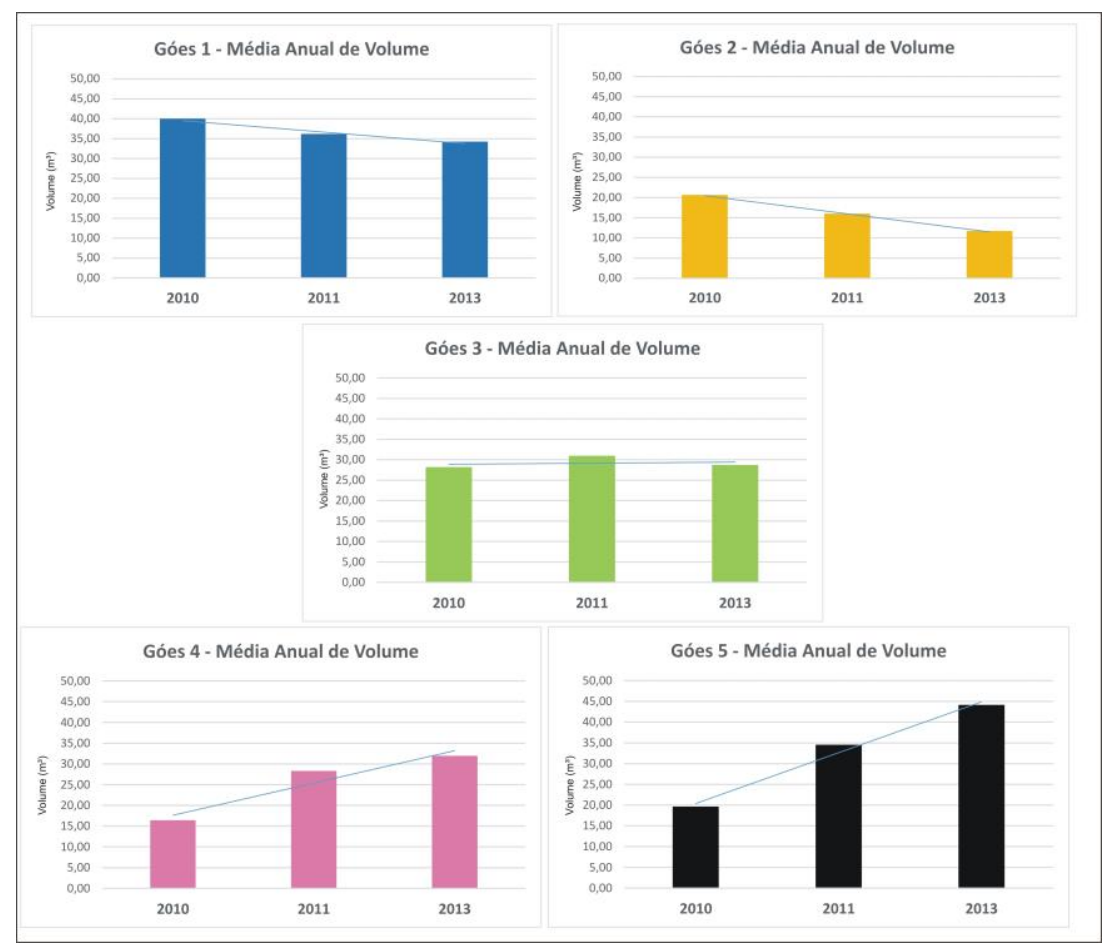

Figura 14: Média anual dos volumes de cada perfil de monitoramento e tendência de balanço sedimentar.

O balanço sedimentar total para os 50 anos foi levemente positivo, com ganho de 7.285,05 $\mathrm{m}^{3}$ de sedimentos, ou seja, uma taxa de incremento de $+145,7$ $\mathrm{m}^{3} /$ ano. Esse aumento corresponde a quase $5 \%$ do volume inicial, podendo-se considerar um balanço sedimentar de longo termo em equilíbrio.

Entretanto, mais importante do que o balanço de longo termo, é o balanço sedimentar entre situações que representem fases similares de um ciclo de transporte e de maior estabilidade morfodinâmica (pico de transporte anti-horário), como em 1972 e 2009. Entre ambas as fases o balanço sedimentar foi de apenas $+43,64 \mathrm{~m}^{3}$, ou seja, uma taxa de incremento de $1,15 \mathrm{~m}^{3} /$ ano $(0,36 \%$ do volume inicial). Portanto, nessas condições, o balanço sedimentar da praia também se mostrou em equilíbrio.

\section{Considerações Finais}

Nas últimas 5 décadas a Praia do Góes tem sofrido variações morfodinâmicas importantes, que refletem dois ciclos de transporte longitudinal: um mais longo, com duração aproximada de 20 anos, em que o sentido principal é o anti-horário, ou seja, de leste para oeste, definindo a condição morfodinâmica mais natural e estável dessa praia; e outro, com duração de cerca de 13 anos, em que a praia passa a ser afetada pelo transporte de sentido horário, portanto de oeste para leste, quando ocorre o fenômeno de rotação praial e se instala uma condição morfológica menos estável.

$\mathrm{O}$ ciclo atual de rotação praial se iniciou em fevereiro/2010. O ciclo anterior teria ocorrido entre maio/1977 e abril/1990. Fases agudas de transporte longitudinal de sentido anti-horário, pouco anteriores a fases de rotação praial, foram constatadas nos anos de 1972 e 2009. Levando em consideração os intervalos de tempo propostos para os ciclos de transporte, então o ciclo atual de rotação praial deverá finalizar em 2022, quando a deriva litorânea resultante de sentido antihorário voltará a predominar até pelo menos 2042. Uma ressalva deve ser feita aqui sobre essas projeções, pois alterações na dinâmica de eventos extremos advindas das mudanças climáticas globais poderão diminuir o intervalo temporal desses ciclos.

A longa duração dos ciclos de transporte e a defasagem temporal de ambos são padrões esperados em função das características fisiográficas da praia e da Enseada do Góes.

Os balanços sedimentares obtidos para o médio e o longo termo nessa praia mostraram equilíbrio e tendências levemente positivas, sugerindo que ela está sob controle geológico e tende a um equilíbrio morfodinâmico nas diferentes escalas temporais.

As condições necessárias para ocorrerem inversões no sentido do transporte são pelo menos duas: uma situação morfológica de fundo muito instável e determinada pelo assoreamento intenso e desequilibrado em uma das extremidades da Enseada do Góes; e a ocorrência de um evento meteorológicooceanográfico de forte magnitude, capaz de gerar ondas de mais de $1,5 \mathrm{~m}$ arrebentando na face praial. A evolução do processo e a resposta morfológica da praia, que resulta em realinhamento da linha de costa, 
Papel da praia na proteção da costa e as alterações oceanográficas em diferentes escalas temporais

ocorrem em pulsos condicionados por eventos de alta energia.

$\mathrm{Na}$ fase mais proeminente do ciclo da rotação praial atual, ocorrida entre fevereiro/2010 e maio/2011, verificou-se um rápido empilhamento sedimentar no setor leste da praia controlado pelo transporte de sentido horário acompanhado de transporte costaadentro muito efetivo. Após essa fase, a praia sofreu um reafeiçoamento morfológico gradual, determinado por inversões esporádicas no sentido da deriva litorânea e por transportes costa-afora (para o largo da Enseada do Góes). Processos semelhantes devem ocorrer durante o ciclo de transporte de sentido antihorário, embora com magnitude e velocidade bem menores.

Os resultados obtidos neste estudo indicam que essas alternâncias de sentido de transporte são essencialmente naturais e independentes das obras de dragagem de aprofundamento do Canal do Porto, sejam as realizadas entre 2010-2011, ou as anteriores, e de menor vulto, ocorridas os anos em 1966 e entre 19721975. Na verdade, talvez seja o conjunto de fatores que controla esses ciclos naturais o principal indutor do intenso assoreamento do canal de navegação.

A grande variabilidade morfodinâmica, volumétrica e granulométrica observada na Praia do Góes em escalas temporais de médio a longo termo, caracterizada por inversões nas larguras praiais e nos volumes do envelope sedimentar entre os setores opostos da praia, mas com variações pouco significativas na parte central da praia (ponto pivô), além de alterações bruscas na granulometria das areias e balanço sedimentar em equilíbrio, se assemelha em muito ao fenômeno de rotação praial descrito para diversas praias na Austrália, EUA, Índia, Ásia e Brasil.

\section{Agradecimentos}

A autora agradece à Companhia Docas do Estado de São Paulo (CODESP) e à Secretaria Especial dos Portos pelo suporte financeiro do PMPPr. Também agradece a toda a equipe que participou dos trabalhos relacionados a esta praia, em especial aos: Geól. MSc. Agenor P. Souza, Geógs. Reinaldo S. Ferreira e Graciele C. Luna, Engs. Manuel L. Gouveia, Mayra C. de Assis e Johann C. Lima, Oceanógs. Eduardo G. Rosa e Nery Conti Neto, e à graduanda em Geologia Mariana C. G. Cascarelli.

\section{Referências}

Alegria-Arzaburu A.R. de, Masselink G. 2010. Storm response and beach rotation on a gravel beach, Slapton Sands, U.K. Marine Geology, 278: 77-99.

Alencar Jr A.C.B. de, Klein A.H. Da F., Araujo R.S. 2011. Modelagem numérica do fenômeno de rotação praial: uma abordagem teórica. V Simpósio Brasileiro de Oceanografia. Resumos (CD-ROM).

Anthony E.J., Gardel A., Dolique F., Guiral D. 2002. Short-term changes in the plan- shape of a sandy beach in response to sheltering by a nearshore mud bank, Cayenne, French Guiana. Earth Surface Processes and Landform, 27: 857-866.

Archetti R., Romagnoli C. 2011. Analysis of the effects of different storm events on shoreline dynamics of an artificially embayed beach. Earth Surface Processes and Landforms. Disponível em: wileyonlinelibrary.com. Acesso em: abril 2014.

Carter R.W.G. 1988. Coastal Environments. An Introduction to the Physical, Ecological and Cultural Systems of Coastlines. Academic Press. 617p.

Codesp/Fundação Ricardo Franco. 2006. Dragagem de Aprofundamento do Canal de Navegação, Bacias de Evolução e Berços de Atracação do Porto Organizado de Santos - São Paulo. CODESP (inédito), Porto de Santos. RIMA, vol. III, p. 1327.

Codesp/Fundação Ricardo Franco. 2008. Dragagem de Aprofundamento do canal de Navegação, Bacias de Evolução e Berços de Atracação do Porto de Santos. EIA, vol. 1, 113p. (inédito).

Cooper J.A.G., Jackson D.W.T., Navas F., Mckenna, J., Malvez G. 2004. Identifying storm impacts on an embayed, high-energy coastline: examples from western Ireland. Marine Geology, 210: 261-280.

Fairley I., Davidson M., Kingston K. 2009. The morphodynamics of a beach protected by detached breakwaters in a high energy tidal environment. Journal Coastal Research, SI 56: 607-611.

Finkelstein K. 1982. Morphological variations and sediment transport in crenulate-bay beaches, Kodiak Island, Alaska. Marine Geology, 47: 261-281.

Hanslow D.J. 2007. Beach erosion trend measurement: a comparison of trend indicators. Journal Coastal Research, SI 50: 588-593.

Harari J., Camargo R. 1995. Tides and mean sea level variabilities in Santos (SP), 1944 to 1989. Relatório Interno do Instituto Oceanográfico da USP, n. 36, 15 p.

Harari J., Kato V.M., Uehara, S.A, Nonnato L.V., Vicentini Neto F.L., Szajnbok C. 2010. Measurements and modeling of sea level and currents in Santos coastal area (São Paulo State, Brazil). Afro-America Gloss News, 13(2): 1-15.

Holman R.A., Symonds G., Thornton E.B., Ranasinghe R. 2006. Rip spacing and persistence on an embayed beach. Journal of Geophysics Research, 111: C01006.

Hsu J.R.C., Evans C. 1989. Parabolic bay shapes and applications. Proceedings Institution of Civil Engineers. London: Thomas Telford, Part 2, 557-570.

INPE - Instituto De Pesquisas Espaciais 2014. El Niño e La Niña. Disponível em http://http://enos.cptec.inpe.br/ Acesso em abril/2014

Jackson D.W.T., Cooper J.A.G. 1984. Geological control on beach form: accommodation space and contemporary dynamics. Journal Coastal Research, SI 56: 69-72.

Klein A.H.F., Benedet Filho L., Schumacher D.H. 2002. Short-term beach rotation process in distinct headland bay beach system. Journal Coastal Research, 18(3): 442-458.

Lee G., Nicholls R.J., Birkemeier W.A. 1998. Storm-driven variability of the beach nearshore profile at Duck, North Carolina, USA, 1981-1991. Marine Geology, 148: 163-177p.

Martins C.C., Mahiques M.M., Dias J.M.A. 2010. Daily morphological changes determined by high- energy events on an embayed beach: a qualitative model. Earth Surface Processes and Landforms, 35: 487-495.

Masselink G. 1999. Alongshore variation in beach cusp morphology in a coastal embayment. Earth Surface Processes and Landforms, 24: 335-347.

Masselink, G., Short, A.D. 1993. The effect of the tide range on beach morphodynamics and morphology: a conceptual beach model. Journal of Coastal Research, 9 (3): 785-800.

Morton R.A., Gibeaut J.C., Paine J.G. 1995. Mesoscale transfer of sand during and after storms - implications for prediction of shoreline movement. Marine Geology, 126: 161-179.

Newe J., Peteres K., Dette H.H., 1999. Profile development under storm conditions as a function of the beach slope. Coastal Sediments, 99(1): 2582-2596.

Quartel S., Kroon A., Ruessink B.G. 2008. Seasonal accretion and erosion patterns of a microtidal sandy beach. Marine Geology, 250: 19-33.

Ojeda E., Guillén J. 2008. Shoreline dynamics and beach rotation of artificial embayed beaches. Marine Geology, 253: 51-62.

Ojeda E., Guillén J., Ribas F. 2006. Bar and shoreline coupling in artificial embayed beaches. Proceedings of the $30^{\text {th }}$ International Conference on Coastal Engineering, p. 2714-2725. 
Papel da praia na proteção da costa e as alterações oceanográficas em diferentes escalas temporais

Ojeda E., Guillén J., Ribas F. 2010. The morphodynamic responses of artificial embayed beaches to storm events. Advances in Geosciences, 26: 99-103.

Ranasinghe R., Mcloughlin R., Short A.D., Symoads G. 2004. The Southern Oscillation Index, wave climate, and beach rotation. Marine Geology, 204: 273-287.

Rooney J.J.B., Fletcher C.H. 2005. Shoreline change and Pacific climate oscillations in Kihei, Maui, Hawaii. Journal Coastal Research, 21: 535-547.

Sedrati M., Anthony E.J. 2007. A brief overview of plan-shape disequilibrium in embayed beaches: Tangier Bay (Morocco). Mediterranée $108 . \quad$ Disponível em: http://mediterranee.revues.org/index190.html?file $1 / 41$. Acesso em: abril/ 2014

Silvester R. 1960. Stabilization of sedimentary coastlines. Nature 188: $467-469$.

Silvester R., Hsu J.R.C. 1993. Coastal Stabilization: innovative concepts. Englewood Cliffs, New Jersey: Prentice Hall, 578p.

Short A.D. (ed.) 1999. Handbook of Beach and Shoreface Morphodynamics. John Wiley \& Sons, NJ, USA. 379p.

Short A.D., Masselink G. 1999. Embayed and structurally controlled beaches. In: Short, A.D. (ed.) Handbook of Beach and Shoreface Morphodynamics. John Wiley \& Sons, NJ, USA. p. 230-250.

Short A.D., Trembanis A.C. 2004. Decadal scale patterns of beach oscillation, and rotation: Narabeen Beach, Australia: Time series PCA and wavelet analysis. Journal of Coastal Research, 20(2): 523-532.

Short A.D., Trembanis A.C., Turner I.L. 2000. Beach oscilation, rotation, and the Southern Oscilation, Narraben Beach, Australia. Proceedings $27^{\text {th }}$ International Coastal Engineering Conference, Sydney, Australia, p. 2439-2452.

Souza C.R. de G. 2007. Determination of net shore-drift cells based on textural and morphological gradations along foreshore of sandy beaches. Journal of Coastal Research, SI 50: 620-625.

Souza, C.R. de G. 2008. Erosão na Praia do GonzaguinhaMilionários (São Vicente, SP): causas e projeções. VII Simpósio Nacional de Geomorfologia (SINAGEO) e II Encontro Latinoamericano de Geomorfologia, Belo Horizonte. Anais. CD-ROM.

Souza C.R. de G. 2009. A Erosão nas Praias do Estado São Paulo: Causas, Consequências, Indicadores de Monitoramento e Risco. In: Memórias do Conselho Científico da Secretaria do Meio Ambiente: A Síntese de um Ano de Conhecimento Acumulado. Bononi V.L.R., Santos Júnior N.A. (Org.). Secretaria do Meio Ambiente do Estado de São Paulo. Instituto de Botânica/SMA. p. 48-69.

Souza. C.R. de G. 2010. Impactos das mudanças climáticas no litoral do Estado de São Paulo (Sudeste do Brasil). VI Seminário Latino Americano de Geografia Física e II Seminário Ibero Americano de Geografia Física, Coimbra, Portugal. Actas. Disponível http://www.uc.pt/fluc/cegot/VISLAGF/actas/tema4/celia regina.

Souza C.R. de G. 2011. Rotação praial na Praia do Góes (Guarujá, SP/Brasil). XIV Congresso Latino-Americano de Ciências do Mar - COLACMAR, Balneário Camboriú (SC). Resumos Expandidos, CD-ROM.

Souza, C.R. de G. 2012. Praias arenosas oceânicas do Estado de São Paulo (Brasil): Síntese dos conhecimentos sobre morfodinâmica, sedimentologia, transporte costeiro e erosão costeira. Revista do Departamento de Geografia-USP, n. 2012, Volume Especial 30 anos, p. 308-371. Disponível em: http://citrus.uspnet.usp.br/rdg/ojs/index.php/rdg/article/view/394

Souza C.R. de G., Luna G.C. 2009. Taxas de retrogradação e balanço sedimentar em praias sob risco muito alto de erosão no município de Ubatuba (Litoral Norte de São Paulo). Quaternary and Environmental Geosciences, 1(1): 25-41. Disponível em: http://ojs.c3sl.ufpr.br/ojs2/index.php/abequa/issue/view/814.

Souza C.R. de G., Luna G.C. 2010. Variação da linha de costa e balanço sedimentar de longo período em praias sob risco muito alto de erosão no município de Caraguatatuba (Litoral Norte de São Paulo, Brasil). Revista de Gestão Costeira Integrada / Journal of Integrated Coastal Zone Management, 10(2): 179199. Disponível em: http://www.aprh.pt/rgci/revista10f2.html.

Souza C.R. de G., Suguio K. 2003. The coastal erosion risk zoning and the São Paulo State Plan for Coastal Management. Journal Coastal Research, SI 35: 530-592.
Souza C.R. de G., Luna C.G., Souza A.P. 2012b. Variabilidade decadal de uma praia de enseada com fenômeno de rotação praial. $46^{\circ}$ Congresso Brasileiro de Geologia e $1^{\circ}$ Congresso de Geologia dos Países de Língua Portuguesa, Santos. Resumos, CD-ROM

Souza C.R. de G., Souza A.P., Ferreira R.S. 2012a. Monitoramento praial antes e durante as obras de dragagem do Porto de Santos, São Paulo (Brasil). In: Barragán Muñoz J.M. (coord.). Libro de Comunicaciones y Pósters, I Congreso Iberoamericano de Gestión Integrada de Áreas Litorales, Cádiz, Spain, p. 802-812.

Souza C.R. de G., Souza A.P., Rosa E.G. 2013. Avaliação histórica da ocorrência de ressacas na Baixada Santista. XIV Congresso da Associação Brasileira de Estudos do Quaternário ABEQUA, Natal. Resumos, CD-ROM.

Souza C.R. de G., Souza A.P., Ferreira R.S., Rosa E.G., Munarin P.C. 2011. Programa de monitoramento praial para avaliação de possíveis impactos da dragagem de aprofundamento do canal do porto de Santos: síntese da abordagem metodológica. XIII Congresso da Associação Brasileira de Estudos do Quaternário ABEQUA e III Encontro do Quaternário Sul-Americano, Búzios. Boletim de Resumos Expandidos. Disponível em: http://www.abequa.org.br/trabalhos/CELIA_SOUZA_PMPPr.pd f.

Thomas T., Phillips M.R., Williams A.T. 2010. Mesoscale evolution of a headland bay: Beach rotation process. Geomorphology, 123: 29-41.

Thomas T., Phillips M.R., Williams A.T., Jenkins R.E. 2011. Shortterm beach rotation, wave climate and the North Atlantic Oscillation (NAO). Progress in Physical Geography, 35(3): 333 352.

Trenhaile A.S. 1987. The Geomorphology of Rock Coasts. Oxford University Press, Oxford, UK. 393p.

Recebido 15 de novembro de 2014 Aceito 06 de fevereiro de 2015 